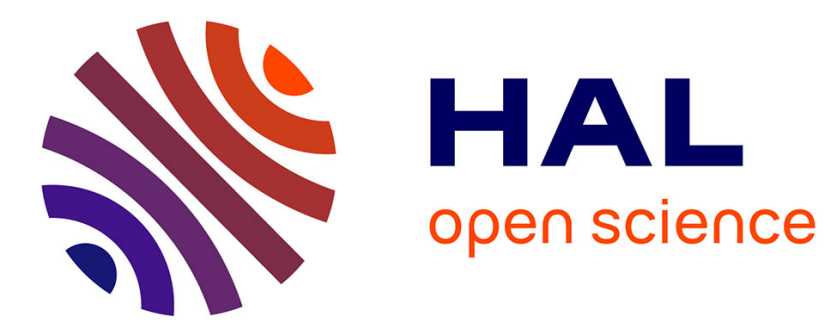

\title{
Design and fabrication of highly reducible PtCo particles supported on graphene-coated $\mathrm{ZnO}$
}

Wen Luo, Walid Baaziz, Qing Cao, Housseinou Ba, Rachid Baati, Ovidiu

Ersen, Cuong Pham-Huu, Spyridon Zafeiratos, Spiros Zafeiratos

\section{To cite this version:}

Wen Luo, Walid Baaziz, Qing Cao, Housseinou Ba, Rachid Baati, et al.. Design and fabrication of highly reducible PtCo particles supported on graphene-coated ZnO. ACS Applied Materials \& Interfaces, In press. hal-03550950

\section{HAL Id: hal-03550950 \\ https://hal.science/hal-03550950}

Submitted on 1 Feb 2022

HAL is a multi-disciplinary open access archive for the deposit and dissemination of scientific research documents, whether they are published or not. The documents may come from teaching and research institutions in France or abroad, or from public or private research centers.
L'archive ouverte pluridisciplinaire HAL, est destinée au dépôt et à la diffusion de documents scientifiques de niveau recherche, publiés ou non, émanant des établissements d'enseignement et de recherche français ou étrangers, des laboratoires publics ou privés. 


\section{Design and fabrication of highly reducible $\mathrm{PtCo}$ particles supported on graphene-coated $\mathrm{ZnO}$}

Wen Luo $^{a}$, Walid Baaziz ${ }^{b}$, Qing Cao ${ }^{c}$, Housseinou Ba ${ }^{a}$, Rachid Baati ${ }^{a}$, Ovidiu Ersen ${ }^{b}$, Cuong

Pham-Huu $^{a}$ and Spyridon Zafeiratos ${ }^{a}$

${ }^{a}$ Institut de Chimie et Procédés pour 1'Energie, l'Environnement et la Santé (ICPEES), ECPM,

UMR 7515 CNRS - Université de Strasbourg, 25 rue Becquerel, 67087 Strasbourg Cedex 02,

France

${ }^{\text {b} I n s t i t u t ~ d e ~ P h y s i q u e ~ e t ~ C h i m i e ~ d e s ~ M a t e ́ r i a u x ~ d e ~ S t r a s b o u r g ~(I P C M S), ~ U M R ~} 7504$ du CNRS,

Université de Strasbourg, 23 rue du Loess, 67037 Strasbourg Cedex 08, France

${ }^{\mathrm{c}}$ Institut Charles Sadron, University of Strasbourg - CNRS, 23 rue du Loess, BP 84047, 67034

Strasbourg Cedex 2, France

KEYWORDS: graphene, composites, Fischer-Tropsch, cobalt, PtCo alloy 
ABSTRACT: Cobalt particles dispersed on an oxide support form the basis of many important heterogeneous catalysts. Strong interactions between cobalt and the support may lead to irreducible cobalt oxide formation, which is detrimental for the catalytic performance. Therefore, several strategies have been proposed to enhance cobalt reducibility, such as alloying with Pt or utilization of non-oxide supports. In this work we fabricate bimetallic PtCo supported on graphene-coated $\mathrm{ZnO}$ with enhanced cobalt reducibility. By employing a model/planar catalyst formulation we show that the surface reduction of cobalt oxide is substantially enhanced by the presence of the graphene support as compared to bare $\mathrm{ZnO}$. Stimulated by these findings we synthesized a realistic powder catalyst consisting of PtCo particles grafted on graphene-coated $\mathrm{ZnO}$ support. We found that the addition of graphene coating enhances the surface reducibility of cobalt, fully supporting the results obtained on the model system. Our study demonstrates that realistic catalysts with designed properties can be developed based on insights gained from model catalytic formulation.

\section{INTRODUCTION}

Cobalt is an active catalyst for several industrially important reactions such as Fischer-Tropsch synthesis ${ }^{1}$ and hydrogenolysis reactions. ${ }^{2}$ In a typical catalytic formulation, cobalt is dispersed on high surface area support materials using simple preparation methods, like impregnation or precipitation. After preparation, the catalyst undergoes calcination to decompose the cobalt precursor, while the catalytic activation also involves a final reduction step in hydrogen in order to transform oxidized cobalt to the metallic state. ${ }^{3,4}$ The reducibility of cobalt species, both during activation and throughout the catalytic reaction, is a crucial aspect of the catalytic performance. ${ }^{5}$ If stable cobalt oxides are formed after calcinations, higher temperature and longer 
reduction treatments are required. This has been blamed for cobalt particle agglomeration and consecutive loss of active surface area. ${ }^{6}$ In addition, formation of mixed cobalt oxide phases with the support during the catalyst's life cycle, result in a loss of the catalytic activity and hampers catalyst's regeneration. ${ }^{7}$ Therefore, maintaining high reducibility of the cobalt species is one of the long-standing challenges of cobalt-based catalysts.

Two major strategies have been put forward in order to enhance the reducibility of supported cobalt catalysts. First is the addition of noble metal promoters $(\mathrm{Ru}, \mathrm{Rh}, \mathrm{Pt}$ etc.) and second, the use of relatively inert support materials with low reactivity toward cobalt. Among the several tested promoters of cobalt catalysts, Pt is probably the one which is the most commonly used and studied. ${ }^{8-10}$ This is not only due to the enhancement of reducibility, but also due to the synergistic effects of the two metals, which boost the catalytic selectivity, activity, and stability. ${ }^{11}$ Improved performance of bimetallic PtCo catalysts as compared to monometallic cobalt has been reported in many catalytic reactions, such as CO oxidation, ${ }^{12,13}$ Fischer-Tropsch synthesis $^{14}$ and low-temperature fuel cell devices. ${ }^{15,16}$

Non-oxide supports and in particular carbon-based materials, have been used in the past to prevent phenomena such as encapsulation, sintering and oxidation of cobalt. ${ }^{17}$ Recently, graphene has attracted tremendous interest for catalytic applications, ${ }^{18-24}$ mainly due to its high thermal conductivity and electron mobility. However, a major drawbacks of all carbon-supported catalysts is their poor mechanical stability which complicates their shape formulation for industrial applications. ${ }^{25}$ An efficient way to overcome this shortcoming would be to combine the surface chemical properties of carbon materials with the bulk-mechanical properties of oxides, by synthesizing carbon-coated oxide supports. ${ }^{24}$ In the past, hybrid materials consisting of metal and/or oxide-graphene composites have been tested for a wide range of catalytic, 
photocatalytic and electrocatalytic reactions. ${ }^{24,26-30}$ However, in most of the cases graphene sheets were simply decorated with oxide nanoparticles ${ }^{31,32}$ which might be sufficient for some applications, but restrict the use of these materials as catalytic supports. Ideally, in order to overcome the shortcomings of both graphene and oxides and promote the catalytic performance, the nanocomposite material should consist of graphene-coated metal oxide support with high coating stability.

Using model planar systems we have recently shown that graphene can effectively modify the cobalt-oxides interactions and tune the redox properties of cobalt under oxygen/hydrogen environment. ${ }^{33,34}$ Our preliminary studies leading to the current work ${ }^{33-35}$ showed that cobalt forms an irreducible mixed oxide with $\mathrm{ZnO}$ even under $\mathrm{H}_{2}$ reduction conditions. This mixed oxide state can be prevented by the insertion of a graphene layer between cobalt and the support. In the present work, we further explore this idea and produce an easily-reducible cobalt catalyst by the addition of $\mathrm{Pt}$ on $\mathrm{Co} /$ graphene/ZnO. Since the surface is critical in the reactivity of catalysts, we focus on the reducibility of the surface by applying XPS analysis after various treatment steps. By using well-defined model catalysts we verify that introduction Pt shifts the reduction of cobalt oxide to distinctly lower temperatures. Furthermore, the reducibility of cobalt oxides is facilitated even further when $\mathrm{ZnO}$ is coated by a graphene layer. Inspired by the finding on the model planar catalyst, and in an attempt to bridge the so called "material gap" in catalysis, we design and synthesize a $\mathrm{PtCo} / g r a p h e n e / \mathrm{ZnO}$ powder catalyst. The improved surface reducibility in $\mathrm{H}_{2}$ was also confirmed for the powder catalyst formulation, opening new routes for the potential exploitation of graphene-covered oxide catalysts in conventional catalytic reactors.

\section{EXPERIMENTAL SECTION}




\section{Materials preparation}

The fabrication process of planar and powder samples, consisting of PtCo particles supported on $\mathrm{ZnO}$ and graphene-coated $\mathrm{ZnO}$ substrates is graphically summarized in figure 1.

Planar/model samples (2D), figure 1a: For the planar/model samples, Zn-terminated ZnO (0001) single crystals $\left(10 \times 10 \times 0.33 \mathrm{~mm}^{3}\right.$, CrysTec GmbH, Germany) were used as substrates. Prior to metal deposition bare $\mathrm{ZnO}$ (abbreviated as $2 \mathrm{D}-\mathrm{ZnO}$ ) and graphene-covered $\mathrm{ZnO}$ (abbreviated as 2D-G@ZnO) were prepared following the procedures described elsewhere. ${ }^{33,35}$ Cobalt and platinum were evaporated under Ultra-High Vacuum (UHV) on freshly-prepared 2D-ZnO and 2D-G@ZnO substrates (abbreviated as $\mathrm{PtCo} / 2 \mathrm{D}-\mathrm{ZnO}$ and $\mathrm{PtCo} / 2 \mathrm{D}-\mathrm{G} @ \mathrm{ZnO}$, respectively), using a commercial e-beam evaporator (Mantis depositions Ltd., model: QUAD-EV-C) attached to the UHV set-up. In order to control the atomic ratio between $\mathrm{Co}$ and $\mathrm{Pt}$, the metal vapor flux was adjusted using integrated metal vapor flux monitors so as to maintain the same deposition time. The base pressure during deposition was better than $1 \times 10^{-8} \mathrm{mbar}$ and the two metals were deposited using pre-calibrated vapor fluxes. For the experiments described here we used 5 min deposition time with Co and Pt deposition rates of $0.06 \mathrm{~nm} / \mathrm{min}$ and $0.02 \mathrm{~nm} / \mathrm{min}$, respectively. Under these conditions, the overall PtCo loading is estimated of about $0.4 \mathrm{~nm}$ and the Co:Pt ratio was kept constant to $3: 1(0.3 \mathrm{~nm} \mathrm{Co} / 0.1 \mathrm{~nm} \mathrm{Pt})$.

Powder samples (3D), figure $1 \mathrm{~b}$ : The preparation of the graphene-coated $\mathrm{ZnO}$ powder sample (abbreviated as 3D-G@ $\mathrm{ZnO}$ ) was based on the synthesis method previously proposed by Son et al. ${ }^{36}$ Initially, graphene oxide (GO) was prepared by oxidation of graphite based on the method of Hummers et al.. ${ }^{37}$ Then, $60 \mathrm{mg}$ of GO were dispersed in $60 \mathrm{~mL}$ dimethylformamide (DMF), and the resulting mixture was ultrasonically treated for $30 \mathrm{~min}$. The produced dispersion liquid was subsequently added slowly to a $\mathrm{Zn}(\mathrm{Ac})_{2} \cdot 2 \mathrm{H}_{2} \mathrm{O}$ DMF solution prepared by dissolving $0.92 \mathrm{~g}$ 
$\mathrm{Zn}(\mathrm{Ac})_{2} \cdot 2 \mathrm{H}_{2} \mathrm{O}$ in $200 \mathrm{~mL}$ DMF under strong agitation. The liquid mixture was stirred for $5 \mathrm{~h}$ at $95{ }^{\circ} \mathrm{C}$. After that, the liquid mixture was centrifugalized and the centrifugate was repeatedly washed with anhydrous ethanol. The final 3D-G@ZnO composite material was obtained after drying at $55{ }^{\circ} \mathrm{C}$ for $12 \mathrm{~h}$. The $\mathrm{ZnO}$ powder sample (3D-ZnO) was prepared starting from $\mathrm{Zn}(\mathrm{Ac})_{2} \cdot 2 \mathrm{H}_{2} \mathrm{O}$ DMF solution and following the same procedure as for the composite material but without the step of GO addition. The co-impregnation method was used to decorate the aforementioned supports with bimetallic PtCo particles (further abbreviated as PtCo/3D-ZnO and PtCo/3D-G@ZnO). In particular, $13.6 \mathrm{mg} \mathrm{H}_{2} \mathrm{PtCl}_{6} \cdot\left(\mathrm{H}_{2} \mathrm{O}\right)_{6}$ and $14.0 \mathrm{mg} \mathrm{Co}\left(\mathrm{CH}_{3} \mathrm{COO}\right)_{2}$ were dissolved in $1 \mathrm{~mL}$ deionized water. Then, the obtained solution was impregnated onto $130 \mathrm{mg}$ of the support (3D-ZnO or 3D-G@ $\mathrm{ZnO}$ ). The obtained precursor was then dried at $80{ }^{\circ} \mathrm{C}$ overnight. The nominal loading of Pt and Co is $4.0 \mathrm{wt} \%$ and $3.6 \mathrm{wt} \%$, respectively, and the atomic ratio of $\mathrm{Pt}$ and $\mathrm{Co}$ is about $1: 3$ as in the case of the model/planar sample. The only impurity which was detected in the survey XPS spectrum was traces of $\mathrm{Cl}$ from the $\mathrm{H}_{2} \mathrm{PtCl}_{6} \cdot\left(\mathrm{H}_{2} \mathrm{O}\right)_{6}$ precursor. The $\mathrm{Cl}$ $2 p$ peak was identical for both powder samples and remained almost unaffected even after the second redox cycle $\left(\mathrm{O}_{2}\right.$ and $\left.\mathrm{H}_{2}\right)$. Earlier reports suggested that the residual $\left[\mathrm{PtCl}_{6}\right]^{2-}$ complexes that remained after decomposition of the Pt precursor, ${ }^{38}$ are mainly attached to the support and do not influence the Pt properties. 
(a) Preparation of Planar Samples (2D)

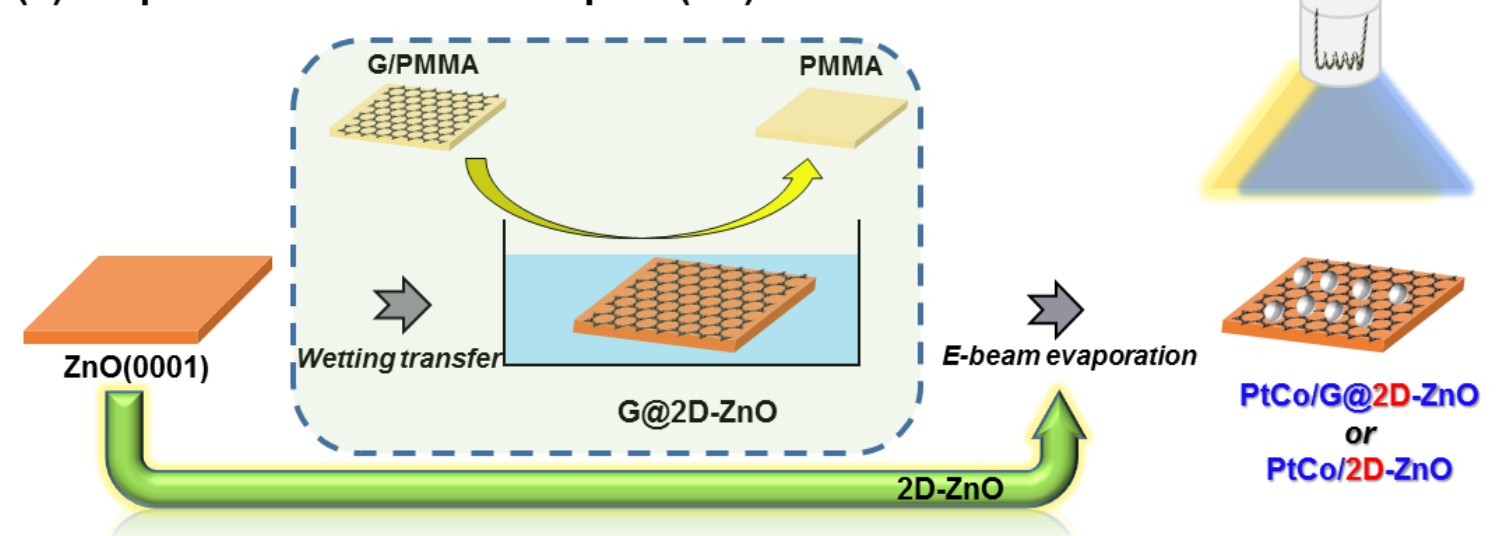

(b) Preparation of Powder Samples (3D)

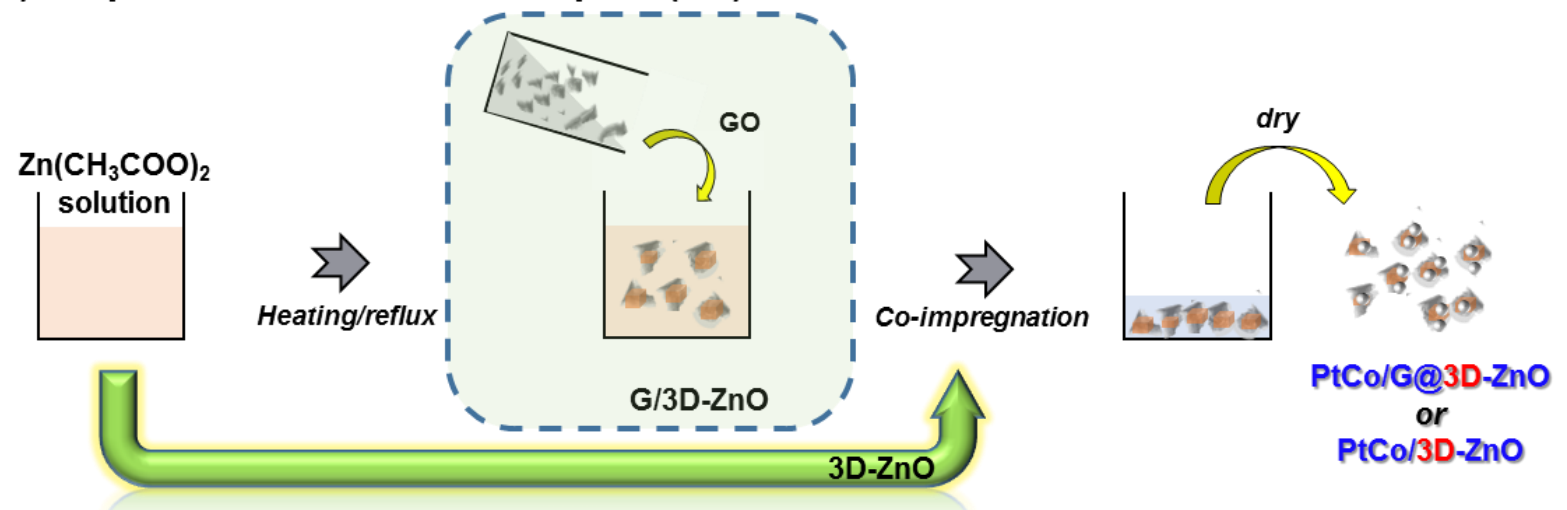

Figure 1. Schematics of sample preparation: (a) PtCo/G@2D-ZnO and (b) PtCo/G@3D-ZnO.

Samples without graphene are prepared following the same synthesis route, with exception the graphene coating step which is highlighted in a coloured background.

\section{Characterization}

The X-ray photoelectron spectroscopy (XPS) measurements were carried out in an UHV setup (base pressure $1 \times 10^{-9}$ mbar) described elsewhere. ${ }^{34}$ The analysis chamber is equipped with VSW Class WA hemispherical electron analyzer (150 mm radius) and a monochromatic $\mathrm{Al} \mathrm{K \alpha}$ X-ray source $(1486.6 \mathrm{eV})$. In the case of the planar substrate, the XPS spectra were recorded at 
normal (0 degree) and grazing (75 degrees) electron take-off angles. The information depth $(d)$ of the XPS measurement is related to the take-off angle $(\theta)$ by the $d=3 \lambda \cdot \cos \theta$ formula, where $\lambda$ the inelastic mean free path of the photoelectrons. ${ }^{33}$ Oxidation/reduction treatments were carried out in a flow-through variable-pressure reactor attached to the UHV setup ( $0.6 \mathrm{~L}$ volume). Each oxidation/reduction step lasted $30 \mathrm{~min}$ at constant temperature and gas pressure. In this way, the consumption of reactant gas $\left(\mathrm{H}_{2}\right.$ or $\left.\mathrm{O}_{2}\right)$ due to the reaction can be ignored and no pressure drop was observed during the experiments. The pressure of the gas $\left(\mathrm{H}_{2}\right.$ or $\left.\mathrm{O}_{2}\right)$ treatment was 7 mbar for the planar samples and 300 mbar for the powder samples. Since the redox behaviour of planar and powder samples is compared qualitatively and not quantitatively, this pressure difference does not influence the discussion. Subsequently to the gas treatment, the sample was cooled to room temperature in gas and the reactor was evacuated to $5 \times 10^{-8} \mathrm{mbar}$. Then the sample was transferred in vacuum into the analysis chamber for XPS characterization. In order to monitor the changes in the oxidation state of cobalt, reference spectra of metallic cobalt $\left(\mathrm{Co}^{0}\right)$, $\mathrm{CoO}$ and $\mathrm{Co}_{3} \mathrm{O}_{4}$ were acquired, matching to the cobalt oxidation states of $\mathrm{Co}^{0}, \mathrm{Co}^{2+}$ and $\mathrm{Co}^{2.67+}$, respectively. The average valence state $x\left(\mathrm{Co}^{x+}\right)$ of cobalt is obtained after linear combination of the $\mathrm{Co} 2 \mathrm{p}$ spectra using the $\mathrm{Co}_{3} \mathrm{O}_{4}, \mathrm{CoO}$ and $\mathrm{Co}$ reference components, under the assumption that the atomic sensitivity factors are the same for all states. A similar method was also applied to analyse the oxidation state of Pt. The analysis of the $\mathrm{Zn} 2 \mathrm{p}$ spectra is less straightforward. According to the characteristic $\mathrm{Zn} 2 \mathrm{p}$ spectra shown in Figure S1, during the thermal treatment there is a small shift (ca. $0.1 \mathrm{eV}$ ) of the $\mathrm{Zn} 2 \mathrm{p}_{3 / 2}$ peak. Literature reports, ${ }^{39,40}$ indicate that the $\mathrm{Zn}$ $2 p$ line is not particularly sensitive to the changes of the chemical environment around $\mathrm{Zn}$ atoms (only $0.3 \mathrm{eV}$ BE shift between metallic $\mathrm{Zn}$ and $\mathrm{ZnO}$ ). Therefore is very difficult to differentiate the chemical state of $\mathrm{Zn}$ atoms based on XPS results. This is further complicated by the fact that 
the signal of $\mathrm{Zn}$ atoms at the interface with the overlayer overlaps with the $\mathrm{Zn} 2 \mathrm{p}$ signal of the bulk $\mathrm{ZnO}$ crystal. Taking into account the above described uncertainties in this study we avoid drawing any conclusions about the chemical state of $\mathrm{Zn}$.

Raman spectra were acquired at room temperature and atmospheric conditions using a microRaman spectrometer (Horiba LabRam), with excitation wavelength of $532 \mathrm{~nm}$. A 100× objective was used to focus the excitation laser to an approximately $1 \mu \mathrm{m}$ spot with a laser power of less than $1 \mathrm{~mW}$ to avoid heating and damage of the sample. X-ray diffraction (XRD) measurements were carried out on a Bruker D-8 Advance diffractometer equipped with a Vantec detector. The powdered sample was packed onto a glass slide.

The morphology of the planar samples was investigated by an AFM microscope (NTEGRA Aura from NT-MDT) at ambient conditions and under tapping mode operation, using probes with typical tip radius of less than $7 \mathrm{~nm}$ (NANOSENSORS PPP-NCHR). Due to the low contrast of the smooth sample surface, as well as the small deposition amount of metals, the scanning electron microscopy (SEM) resolution is limited for these samples and thus atomic force microscopy (AFM) was used. In the case of powder samples a JEOL JSM-6700F scanning electron microscope was used. The TEM analysis was carried out on a JEOL $2100 \mathrm{~F}$ working at $200 \mathrm{kV}$ accelerated voltage, equipped with a probe corrector for spherical aberrations, and a point-to-point resolution of $0.2 \mathrm{~nm}$. The sample was dispersed by ultrasounds in an ethanol solution for 5 minutes and a drop of the solution was deposited on a copper covered with a holey carbon membrane for observation.

\section{RESULTS AND DISCUSSION}

Preparation and characterization of planar samples (2D) 
The quality of the graphene layer on the graphene-coated $\mathrm{ZnO}(0001)$ before and after PtCo deposition was characterized by Raman spectroscopy (Figure 2a). The G and 2D bands at around $1580 \mathrm{~cm}^{-1}$ and $2700 \mathrm{~cm}^{-1}$ are known to arise from the in-plane vibrational $\left(\mathrm{E}_{2 \mathrm{~g}}\right)$ mode and the two phonon intervalley double resonance scattering of graphene, ${ }^{41}$ respectively. For the fresh 2D-G@ZnO sample, the narrow symmetric 2D band and the relatively high 2D/G bands intensity ratio confirm that graphene is in single layer form. ${ }^{42}$ After PtCo deposition, an additional peak at $\sim 1350 \mathrm{~cm}^{-1}$ (D band) appears in the Raman spectrum due to the formation of defects or disorders in the graphene structure. Chemisorbed-type interactions of metals such as $\mathrm{Ti}^{43,44} \mathrm{Pd}^{43}$ and $\mathrm{Cr}^{44}$ with graphene can introduce defects in the carbon structure. Moreover, it is known that Pt is weakly bound with graphene, while on the other hand cobalt is chemisorbed and therefore it bonds stronger on graphene. ${ }^{43}$ Therefore it is more likely that the defects observed in the Raman spectra are primarily induced at the cobalt-graphene contact sites, due to dissolution of carbon atoms from graphene into the metal volume, as proposed earlier. ${ }^{34}$
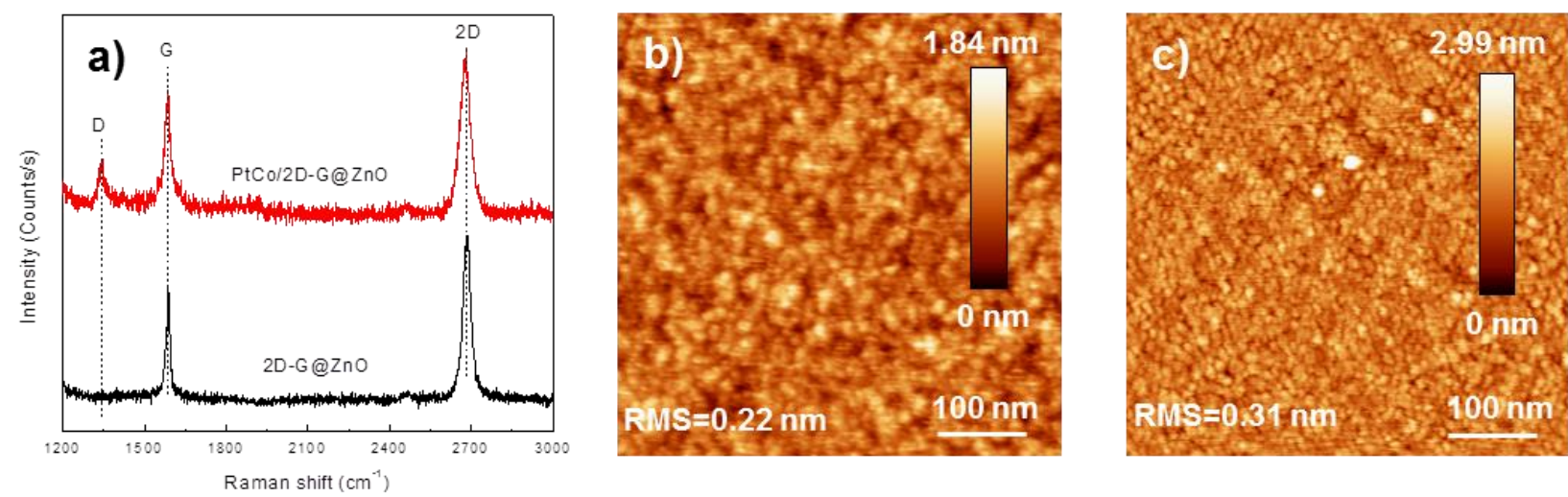

Figure 2. (a) Raman spectra of 2D-G@ZnO and PtCo/2D-G@ZnO. Tapping mode AFM topographic images $(500$ x $500 \mathrm{~nm}$ ) of as prepared (b) PtCo/2D-ZnO and (c) PtCo/2D-G@ZnO. 
The morphology of clean $\mathrm{ZnO}(0001)$ and 2D-G@ $\mathrm{ZnO}$ substrates has been characterized in detail in our previous work. ${ }^{35}$ In Figures $2 b$ and $2 c$ the top-view tapping-mode AFM topographic images just after PtCo deposition at room temperature are presented. Here we need to note that the particles size shown in the AFM images is overestimated due to the convolution of the particles with the AFM tip. Since the AFM tip radius is $\sim 7 \mathrm{~nm}$, the smallest structures which could be resolved here are about 5 to $10 \mathrm{~nm}$. Even though, the identical AFM measurement conditions and parameters still allow us to compare the sample morphology. The PtCo morphology across the $\mathrm{ZnO}$ surface is relatively flat and homogenous with low surface roughness (root mean square, RMS $=0.22 \mathrm{~nm}$ ), which is in agreement with the previous reported morphology of monometallic Co particles on $\mathrm{ZnO}^{33-35,45}$ In the case of PtCo deposition on 2D$\mathrm{G} @ \mathrm{ZnO}$ substrate (fig. 2c), a significant change in the surface morphology is noticed. In particular, PtCo seems to organize in homogeneous and dense nanoparticles (NPs), while the height of the particles increases of about $1 \mathrm{~nm}$ with respect to the value measured for particles on ZnO. The apparent increase of the PtCo particles' size reflects the differences in the deposit/support interaction in the two cases. The weak interaction of PtCo with graphene enhances the metal mobility over the support and is accountable for the formation of a dense nanoparticle structure. ${ }^{33-35,46}$

\section{Comparison of the surface redox stability of $2 \mathrm{D}$ samples}

The PtCo/2D-ZnO and PtCo/2D-G@ZnO samples were treated stepwise under 7 mbar $\mathrm{O}_{2}$ and $\mathrm{H}_{2}$ while XPS was measured after each step to characterize their surface state and composition. Characteristic photoemission Co $2 \mathrm{p}$ XPS spectra and their deconvolution to various cobalt oxidation states are displayed in Figure $3 a$ and $b$. Initially cobalt is metallic (Co $2 p_{3 / 2}$ at 778.6 $\mathrm{eV})$, while after $\mathrm{O}_{2}$ exposure the peak becomes broader due to the contribution of $\mathrm{Co}^{2+}(780.8 \mathrm{eV})$ 
and $\mathrm{Co}^{2.67+}(779.8 \mathrm{eV})$ components. The fitting of the $\mathrm{Co} 2 \mathrm{p}$ spectrum into $\mathrm{Co}^{0}, \mathrm{Co}^{2+}$ and $\mathrm{Co}^{2.67+}$ allows estimating the average cobalt oxidation state of the bimetallic nanoparticles (figure $3 \mathrm{c}$ ). Interestingly, at low temperature, $\mathrm{PtCo} / 2 \mathrm{D}-\mathrm{ZnO}$ complete oxidation to $\mathrm{CoO}$ is found, while for PtCo/2D-G@ZnO, part of Co remains metallic. At the higher temperature about $50 \%$ $\mathrm{Co}^{2+} / \mathrm{Co}^{2.67+}$ ratio is reached for both samples. In our previous work we have shown that without the addition of $\mathrm{Pt}$, Co can be fully oxidized to $\mathrm{Co}_{3} \mathrm{O}_{4}$ at this temperature under 7 mbar $\mathrm{O}_{2} \cdot{ }^{34}$ The current results demonstrate that Pt co-deposition partially prevents Co oxidation in agreement with earlier studies. ${ }^{10,13}$ Certainly one cannot exclude the impact of graphene to Co oxidation clearly observed at low temperature, but it seems that when the oxidation temperature increases, graphene effect is limited.

The planar geometry of the sample allows employing angle-resolved XPS measurements in order to specify if cobalt particles are oxidized preferentially at the surface or at the interface with the substrate. The Co $2 p$ and Pt $4 \mathrm{f}$ spectra were recorded at 0 degree and 75 degree take-off angles, which correspond to analysis information depth for Co $2 \mathrm{p}$ of $\sim 4$ and $1 \mathrm{~nm}$, respectively. As shown in supporting information $\mathrm{S} 2$, in case of $\mathrm{PtCo} / 2 \mathrm{D}-\mathrm{G} @ \mathrm{ZnO}$ there is a clear enhancement of cobalt oxidation in the more surface sensitive measurements, which signifies that oxidation of cobalt starts from the surface and progresses to the interface with graphene. In contrast, for $\mathrm{PtCo} / 2 \mathrm{D}-\mathrm{ZnO}$, XPS spectra of both take-off angles gave almost identical cobalt valence. This result shows that during $\mathrm{PtCo} / 2 \mathrm{D}-\mathrm{ZnO}$ exposure to $\mathrm{O}_{2}$, cobalt oxidation proceeds not only through the surface but also via the interface with the $\mathrm{ZnO}$ support. 

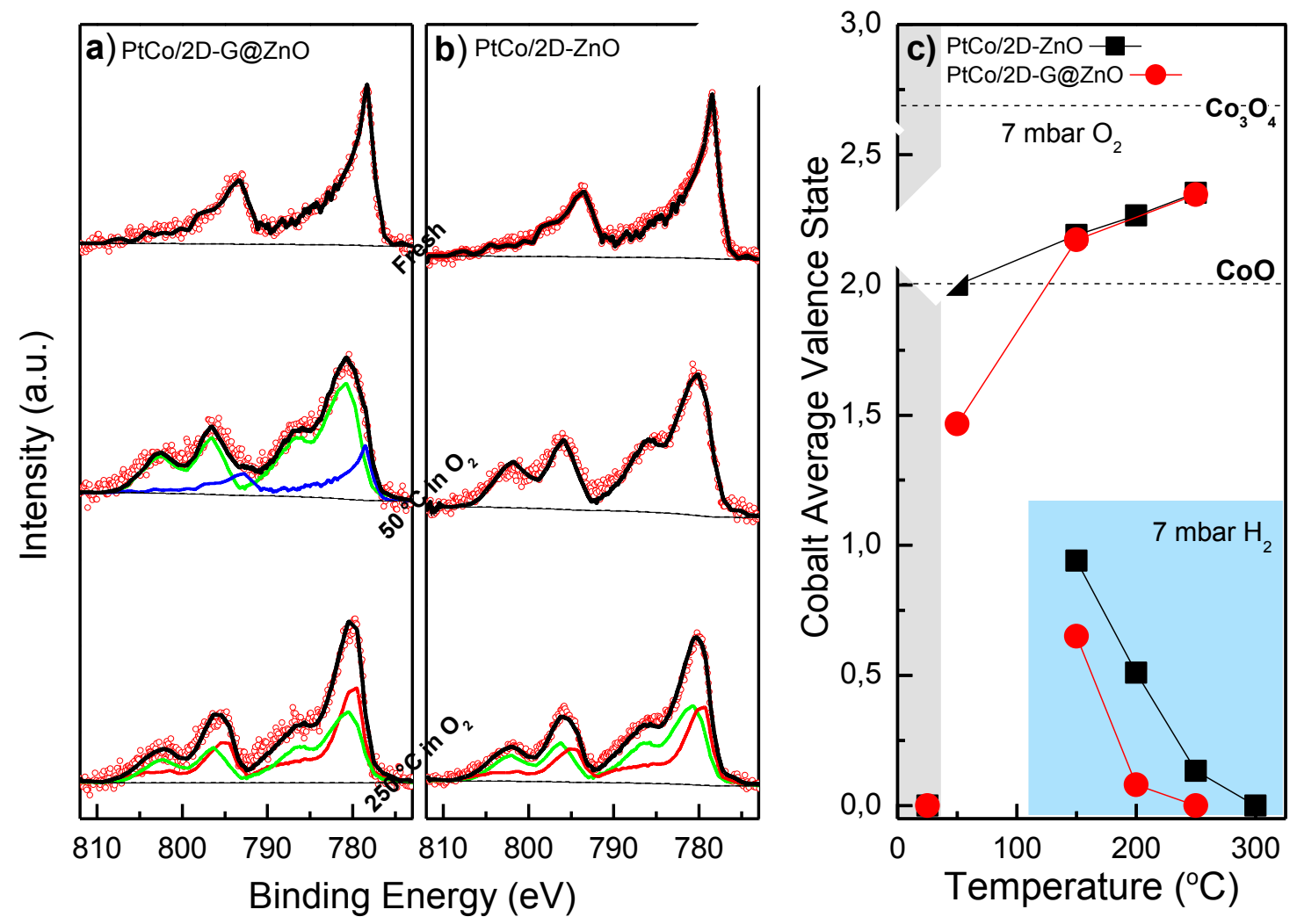

Figure 3. Co 2p XPS spectra acquired from (a) PtCo/2D-ZnO and (b) PtCo/2D-G@ZnO after PtCo deposition and oxidation in 7 mbar $\mathrm{O}_{2}$ at 25 and $250{ }^{\circ} \mathrm{C}$ (c) Co average valence state of $\mathrm{PtCo} / 2 \mathrm{D}-\mathrm{ZnO}$ and $\mathrm{PtCo} / 2 \mathrm{D}-\mathrm{G} @ \mathrm{ZnO}$ during the $7 \mathrm{mbar}_{2}$ (with the white background) and 7 mbar $\mathrm{H}_{2}$ treatments (with a cyan background). The initial oxidation states (just after UHV deposition) are shown with a grey background.

The reduction of pre-oxidized cobalt in $7 \mathrm{mbar}_{2}$ is plotted as a function of temperature in a blue background in Figure 3c. As is evident, already at $150{ }^{\circ} \mathrm{C}$ the greater part of pre-oxidized cobalt is reduced. However, comparison of the two samples in each treatment temperature shows that the reduction of cobalt oxide is substantially enhanced in the presence of graphene. Promotion of cobalt oxide reduction by graphene is in accordance with our previous findings of 
monometallic cobalt. ${ }^{33,34}$ The enhanced reduction of cobalt oxides is attributed to the weak interaction between $\mathrm{Co}$ and graphene as compared with that of $\mathrm{ZnO}$ oxides. ${ }^{33,34}$ Moreover, the PtCo particles are reduced at lower temperatures relative to the reports of monometallic Co, ${ }^{34}$ which can be attributed to the ability of Pt to dissociatively adsorb hydrogen and promote cobalt oxide reduction.

We turn now our attention on Pt and present the deconvoluted Pt 4f XPS spectra in Figure 4a and $\mathrm{b}$ together with the evolution of the various $\mathrm{Pt}$ oxide species and the mean Pt valence for $\mathrm{PtCo} / 2 \mathrm{D}-\mathrm{ZnO}$ sample (figure $4 \mathrm{c}$ ). The $\mathrm{Pt} 4 \mathrm{f}_{7 / 2}$ for freshly prepared $\mathrm{PtCo} / 2 \mathrm{D}-\mathrm{ZnO}$ and $\mathrm{PtCo} / 2 \mathrm{D}-$ $\mathrm{G} @ \mathrm{ZnO}$ is found at $71.6 \pm 0.1 \mathrm{eV}$. This energy is about $0.4 \mathrm{eV}$ higher than the one measured on a reference $\mathrm{Pt}$ foil, indicating an electronic interaction of $\mathrm{Pt}$ and $\mathrm{Co}$ due to $\mathrm{PtCo}$ alloy formation. $^{47,48}$ One should exclude here the possibility that the BE shift is induced by a combination of initial and final state effects due to the small Pt particles size. ${ }^{49,50}$ This effect has been observed for Pt nanoparticles with sizes up to $2-3 \mathrm{~nm},{ }^{50}$ while in our case the particles are much bigger as observed in the AFM images. 

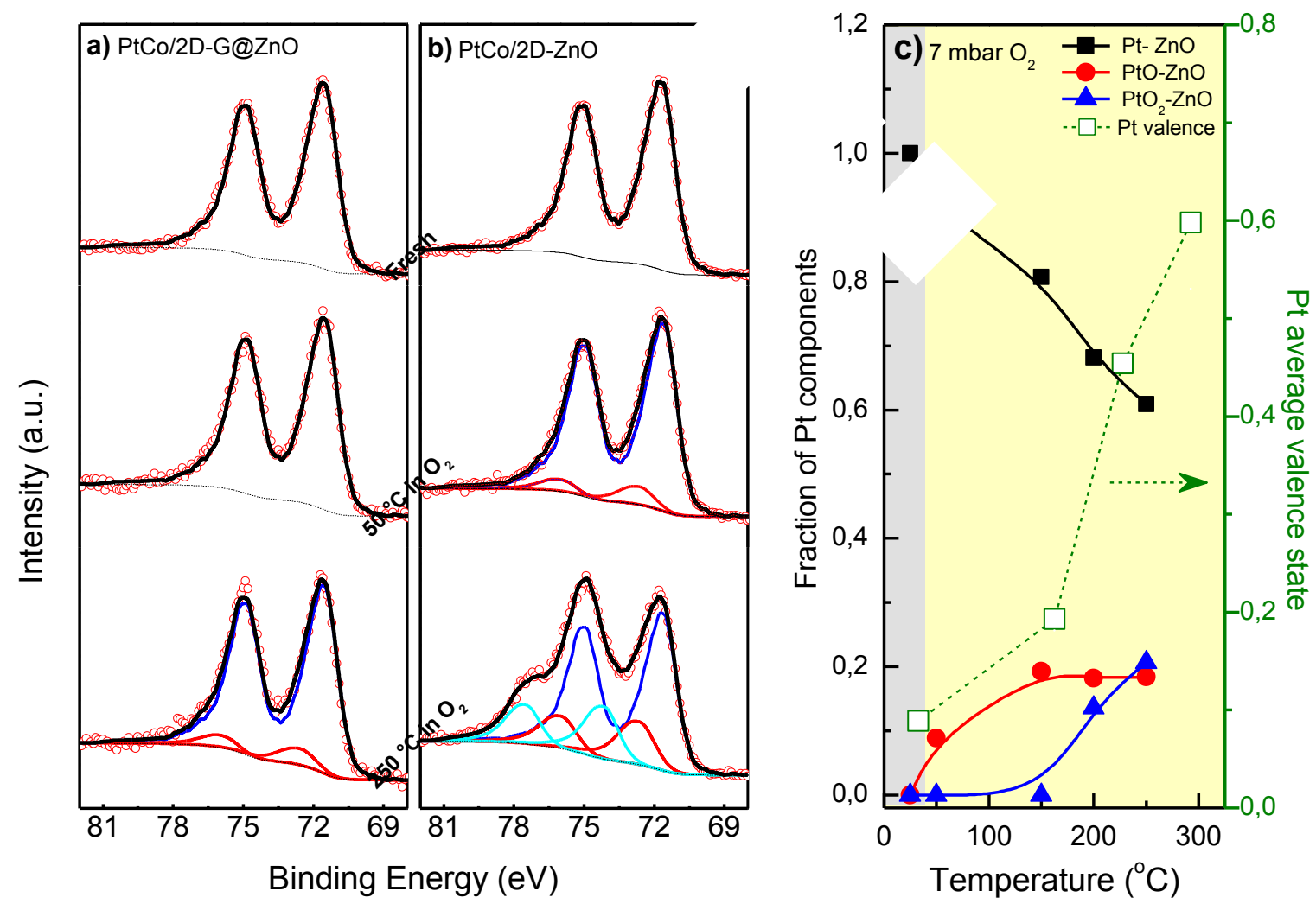

Figure 4. The Pt 4f XPS spectra under various oxidation temperatures in 7 mbar $\mathrm{O}_{2}$ for (a) $\mathrm{PtCo} / 2 \mathrm{D}-\mathrm{ZnO}$ and (b) PtCo/2D-G@ZnO. Deconvolution of the main spectra to metal and oxidized Pt components is included. (c) The evolution of the various Pt oxide species and the mean $\mathrm{Pt}$ valence as a function of temperature at the $\mathrm{PtCo} / 2 \mathrm{D}-\mathrm{ZnO}$ sample. The values in a grey background correspond to the sample just after UHV deposition, while the yellow background is in 7 mbar $\mathrm{O}_{2}$.

Annealing of PtCo/2D-G@ $\mathrm{ZnO}$ in $\mathrm{O}_{2}$ up to $150{ }^{\circ} \mathrm{C}$ does not influence the $\mathrm{Pt}$ 4f spectrum, while an additional component at $72.6 \mathrm{eV}$ is observed at $250{ }^{\circ} \mathrm{C}$. This component is associated to PtO formation ${ }^{51}$ while Pt-Zn surface alloys ${ }^{52}$ should be excluded, since they are only reported at highly reducing conditions. ${ }^{52}$ In the case of $\mathrm{PtCo} / 2 \mathrm{D}-\mathrm{ZnO}, \sim 9 \%$ of the total amount of $\mathrm{Pt}$ is 
oxidized to PtO already at room temperature, while this fraction further increases to $19 \%$ after oxidation at $150{ }^{\circ} \mathrm{C}$. When the temperature rises to $250{ }^{\circ} \mathrm{C}$, a higher oxidation state of $\mathrm{Pt}$, located at $\sim 74.2 \mathrm{eV}$ can be distinguished in the XPS spectrum, which corresponds to $\mathrm{PtO}_{2} \cdot{ }^{51,53}$ The XPS angle-resolved measurements (Figure $\mathrm{S} 2$ ) of $\mathrm{PtCo} / 2 \mathrm{D}-\mathrm{ZnO}$ sample demonstrate a systematically higher amount of oxidized $\mathrm{Pt}$ at the deeper analysis depth, meaning that oxidized $\mathrm{Pt}$ is primarily located at the interface with $\mathrm{ZnO}$. This suggests that $\mathrm{Pt}$ oxidation is related to its interaction with the $\mathrm{ZnO}$ support and not with the gas oxygen. The fact that oxidized $\mathrm{Pt}$ is located at the interface with $\mathrm{ZnO}$, can also explain the reason why Pt oxidation is practically not observed for $\mathrm{PtCo} / 2 \mathrm{D}$ $\mathrm{G} @ \mathrm{ZnO}$, since the particles and $\mathrm{ZnO}$ are not in direct contact. In $7 \mathrm{mbar}_{2}$, oxidized $\mathrm{Pt}$ is completely reduced to the metallic state already at the first annealing step $\left(150^{\circ} \mathrm{C}\right)$ and remains in the metallic state upon heating at higher temperature (data not shown).

The differences in the PtCo oxidation between 2D-G@ ZnO and 2D-ZnO may be attributed to variations in the oxidation mechanisms. When supported PtCo is exposed to gas-phase oxygen, the oxidation of metals initialled with dissociation of $\mathrm{O}_{2}$ molecule to atomic oxygen, together with the mobility of metal atoms on the surface. ${ }^{54}$ Then atomic $\mathrm{O}$ forms a chemisorbed overlayer and oxidizes the surface of the metal particles. This procedure described the oxidation of PtCo from the gas-phase oxygen, as in the case of PtCo/2D-G@ZnO. However, for PtCo/2D-ZnO besides gas-phase oxidation, interface oxidation was also observed due to the direct interaction with $\mathrm{ZnO}$. In that case adsorbed $\mathrm{OH}$ groups on $\mathrm{ZnO}$ may act as the oxygen source. The formation $\mathrm{OH}$ groups on polar $\mathrm{ZnO}$ surface due interaction with residual $\mathrm{H}_{2}$ or $\mathrm{H}_{2} \mathrm{O}$ species has been previously reported and found to oxidize Co at room temperature. ${ }^{40,55}$ At higher temperatures, $\mathrm{ZnO}$ itself could be the reason of PtCo oxidation at the interface, as has been previously observed in noble metal/reducible oxide systems. For example, in $\mathrm{O}_{2}$, the oxidation of 
$\mathrm{ZnO}$-supported $\mathrm{Au}$ at $200{ }^{\circ} \mathrm{C}$ was attributed to $\mathrm{Au}-\mathrm{O}-\mathrm{Zn}$ interactions. ${ }^{56}$ Ceria is also known to stabilize Pt oxides by formation of Pt-O-Ce species, especially at the periphery of the metal particle. ${ }^{57,58}$ Moreover, preferential oxidation of $\mathrm{Pd}$ at the $\mathrm{Pd} / \mathrm{Fe}_{3} \mathrm{O}_{4}$ interface was suggested to stabilize $\mathrm{PdO}$ by the interaction with the $\mathrm{Fe}_{3} \mathrm{O}_{4}$ support. ${ }^{59,60}$ Although is difficult to suggest an unambiguous oxidation mechanism of $\mathrm{PtCo}$, our results confirms that the metal/oxide interface oxidation is taking place on $\mathrm{PtCo} / 2 \mathrm{D}-\mathrm{ZnO}$ sample. Besides, it further proposes that in case of nanoparticles oxidation from the support might be as significant as that of the gas phase oxygen.

The topographic AFM images of PtCo/2D-ZnO and PtCo/2D-G@ZnO after the redox treatment are shown in Figures 5a and b, respectively. As compared to the fresh samples (Figures $2 b$ and c), the redox treatment increases the surface roughness due to agglomeration of the nanoparticles. However, the evolution of their morphology is still influenced by the substrate, similar to the fresh samples. In particular, the $\mathrm{PtCo} / 2 \mathrm{D}-\mathrm{G} @ \mathrm{ZnO}$ surface roughness is higher $(\mathrm{RMS}=0.46)$ as compared to $\mathrm{PtCo} / 2 \mathrm{D}-\mathrm{ZnO}(\mathrm{RMS}=0.40)$.

Agglomeration of PtCo particles is confirmed by the evolution of the Co 2p/Pt 4f peak area ratio plotted in Figure 5c. As shown, for both samples there is an increase of the Co $2 \mathrm{p} / \mathrm{Pt} 4 \mathrm{f}$ ratio in the oxidation process, while the opposite trend is observed upon reduction. These changes reflect the enrichment of the surface with cobalt during oxidation and the reverse process upon reduction. Please note that the Co $2 \mathrm{p} / \mathrm{Pt} 4 \mathrm{f}$ ratio is consistently lower for the graphene sample also including the initial state just after deposition. This tendency was observed in several repeated experiments therefore one can exclude uncertainties of the metal evaporation procedure. We attribute the differences in the Co $2 \mathrm{p} / \mathrm{Pt} 4 \mathrm{f}$ ratio between the two supports, to the higher mobility of $\mathrm{Pt}$ and $\mathrm{Co}$ on graphene as compared to $\mathrm{ZnO}$. The higher atom mobility enhances the surface diffusion of Pt over Co just after deposition and facilitates fusion of the two metals. 
Notably, under higher temperature and $\mathrm{O}_{2}$ pressure the kinetic barriers are lifted, allowing Co to segregate over Pt and oxidize, as dictated by its stronger interaction with oxygen as compared to $\mathrm{Pt}^{54}$

The Raman spectra after the redox treatment are plotted in Figure 5d. As indicated by the high intensity of the D peak as well as of the appearance of an additional D' peak which is also activated by defects on graphene, more defects are generated after the gas treatment. Comparison of the Raman spectra after $\mathrm{O}_{2}$ and $\left(\mathrm{O}_{2}+\mathrm{H}_{2}\right)$ treatments show that most of the defects are generated in $\mathrm{O}_{2}$, while the consequent $\mathrm{H}_{2}$ reduction step has no particular influence on the defect formation. In addition to the Raman results, the XPS spectra provide detailed information about the oxidation state of graphene. As shown in Figure 5e, a single C 1s peak at $284.8 \mathrm{eV}$ can be observed on the fresh PtCo/2D-G@ZnO sample which is from the sp ${ }^{2}$ carbon of graphene. ${ }^{34}$ After $250{ }^{\circ} \mathrm{C}$ oxidation treatment, additional peaks arise at higher binding energies which can be assigned to the oxidized carbon (C-O, $\mathrm{C}=\mathrm{O}$ and $\mathrm{O}-\mathrm{C}=\mathrm{O}$ ) ${ }^{34}$ Annealing in $\mathrm{H}_{2}$ atmosphere could reduce these oxidized carbon species, even though, as shown in Raman spectra, this procedure does not recover the high quality of pristine graphene. These results confirm the previously proposed mechanism of defect formation of graphene induced by cobalt deposition. ${ }^{34}$ In particular, cobalt particles locally dilute carbon atoms of the graphene lattice, making these atoms more vulnerable to oxidation in $\mathrm{O}_{2}$ atmosphere e.g. to $\mathrm{CO}_{2}$, as compared to carbon atoms on uncovered graphene. 

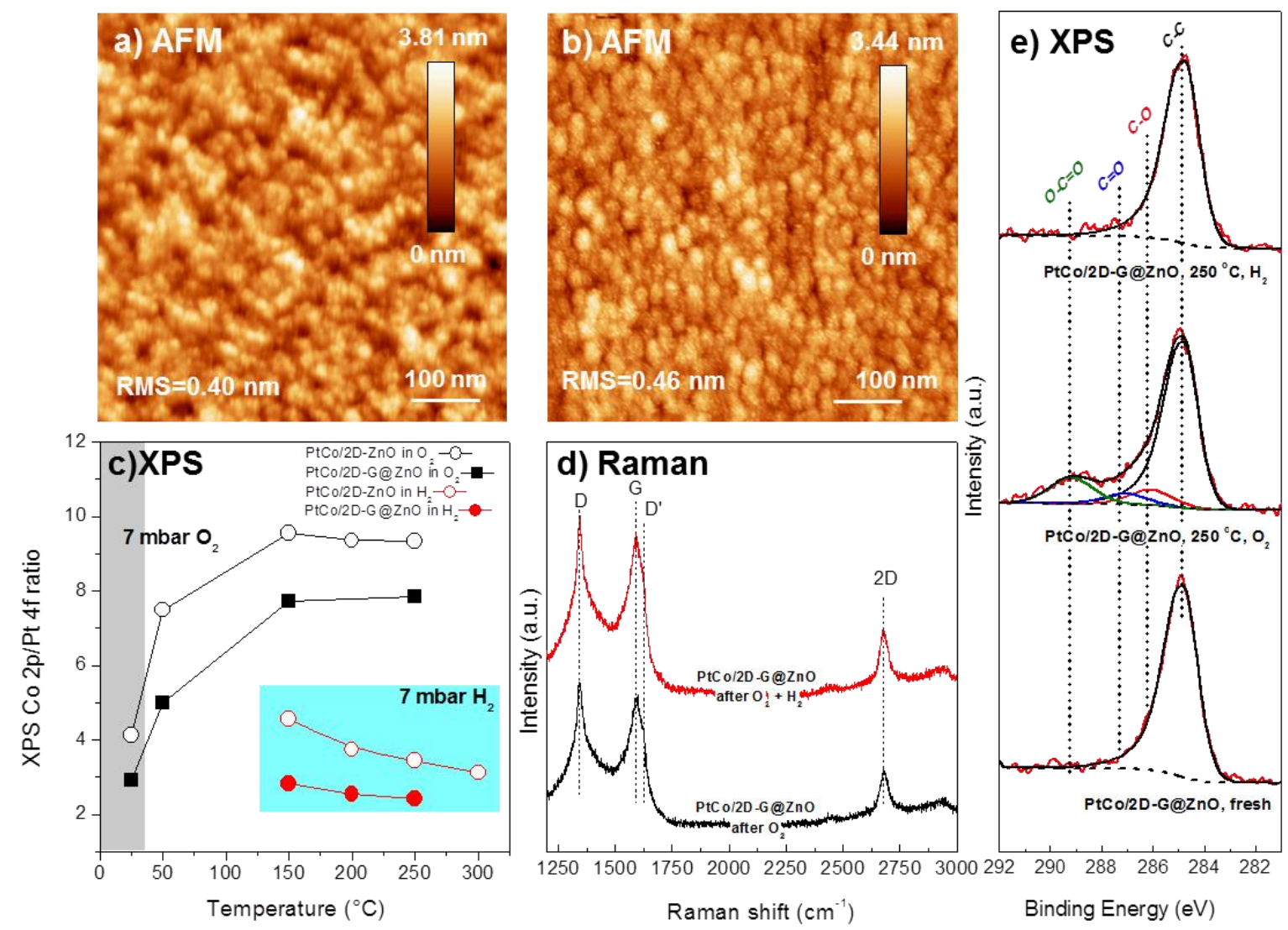

Figure 5. Tapping mode AFM topographic images $(500 \times 500 \mathrm{~nm}$ ) of (a) $\mathrm{PtCo} / 2 \mathrm{D}-\mathrm{ZnO}$ and (b) PtCo/2D-G@ZnO after 7 mbar redox treatments c) the Co 2p/Pt4f XPS peak area ratio as a function of temperature for both $\mathrm{O}_{2}$ and $\mathrm{H}_{2}$ treatments d) Raman spectra of $\mathrm{PtCo} / 2 \mathrm{D}-\mathrm{G} @ \mathrm{ZnO}$ sample after oxidation and reduction treatments e) $\mathrm{C}$ 1s spectra of fresh, oxidized and reduced PtCo/2D-G@ZnO sample.

\section{Preparation and characterization of powder samples (3D)}

The comparative investigation of the planar systems illustrates in detail the effect of graphene layer on the arrangement and the redox properties of PtCo. However, one should be aware that it remains a model system which deviates from the usual high surface area powder catalysts, in terms of both morphology and preparation method. Inspired by the promising results provided by 
the model system we attempt to synthesize analogous materials in a powder form, targeting to $\mathrm{ZnO}$-based catalysts with enhanced cobalt reducibility. The employed synthesis method is selected with the aim to produce a $3 \mathrm{D}$ powder sample with characteristics equivalent to the $2 \mathrm{D}$ graphene-coved $\mathrm{ZnO}$. The Raman spectra of the graphene oxide (GO) precursor and the synthesized 3D-G@ZnO support before PtCo deposition are shown in Figure 6a. The Raman spectra are dominated by the $\mathrm{D}$ and $\mathrm{G}$ bands at 1600 and $1350 \mathrm{~cm}^{-1}$ respectively, resembling the spectra recorded on the 2D model system after the redox treatments (Fig. 5d). The high intensity $\mathrm{D}$ band and the absence of 2D band are clear evidences of the high defect density of graphene in the 3D-G@ZnO. This is not surprising though, since the graphene layers are synthesized based on a GO precursor which has a much higher defect density as compared to the CVD graphene used for the 2D-G@ZnO sample. ${ }^{55}$

The XRD patterns of the as prepared powder substrates plotted in Figure $6 \mathrm{~b}$ exhibit typical diffraction peaks of pure hexagonal wurtzite phase $\mathrm{ZnO}$, in agreement with standard bulk $\mathrm{ZnO}$ pattern (JCPDS no. 36-1451). ${ }^{56}$ The similarity of the diffraction patterns of 3D-ZnO and 3DG@ZnO composites confirms that the crystallinity of the $\mathrm{ZnO}$ particles is not affected by the incorporation of graphene. ${ }^{57}$ Furthermore, the high intensity diffraction peak at a $2 \theta$ value of $11.4^{\mathrm{o}}$ corresponding to the $(001)$ crystal plane of GO is absent on the pattern of 3D-G@ $\mathrm{ZnO}$, which means that stacked GO have been effectively exfoliated during the synthesis process. In addition, no prominent peak of graphite at $2 \theta=26^{\circ}$ can be observed for 3D-G@ZnO, indicating that the restacking of the reduced graphene layers is to a great extent prevented. However, as calculated by the Scherrer's equation, ${ }^{58}$ the average $\mathrm{ZnO}$ crystallite size of $3 \mathrm{D}-\mathrm{G} @ \mathrm{ZnO}$ is $~ 16$ $\mathrm{nm}$ which is considerably smaller than that of $3 \mathrm{D}-\mathrm{ZnO}(\sim 31 \mathrm{~nm})$. This is probably caused during the formation of graphene-coated $\mathrm{ZnO}$, where the graphene fragments detach from the GO layers 
through chemical exfoliation and encircle the $\mathrm{ZnO}$ nuclei, limiting the growth of large $\mathrm{ZnO}$ crystals during the crystallization process of $\mathrm{ZnO} .^{36}$
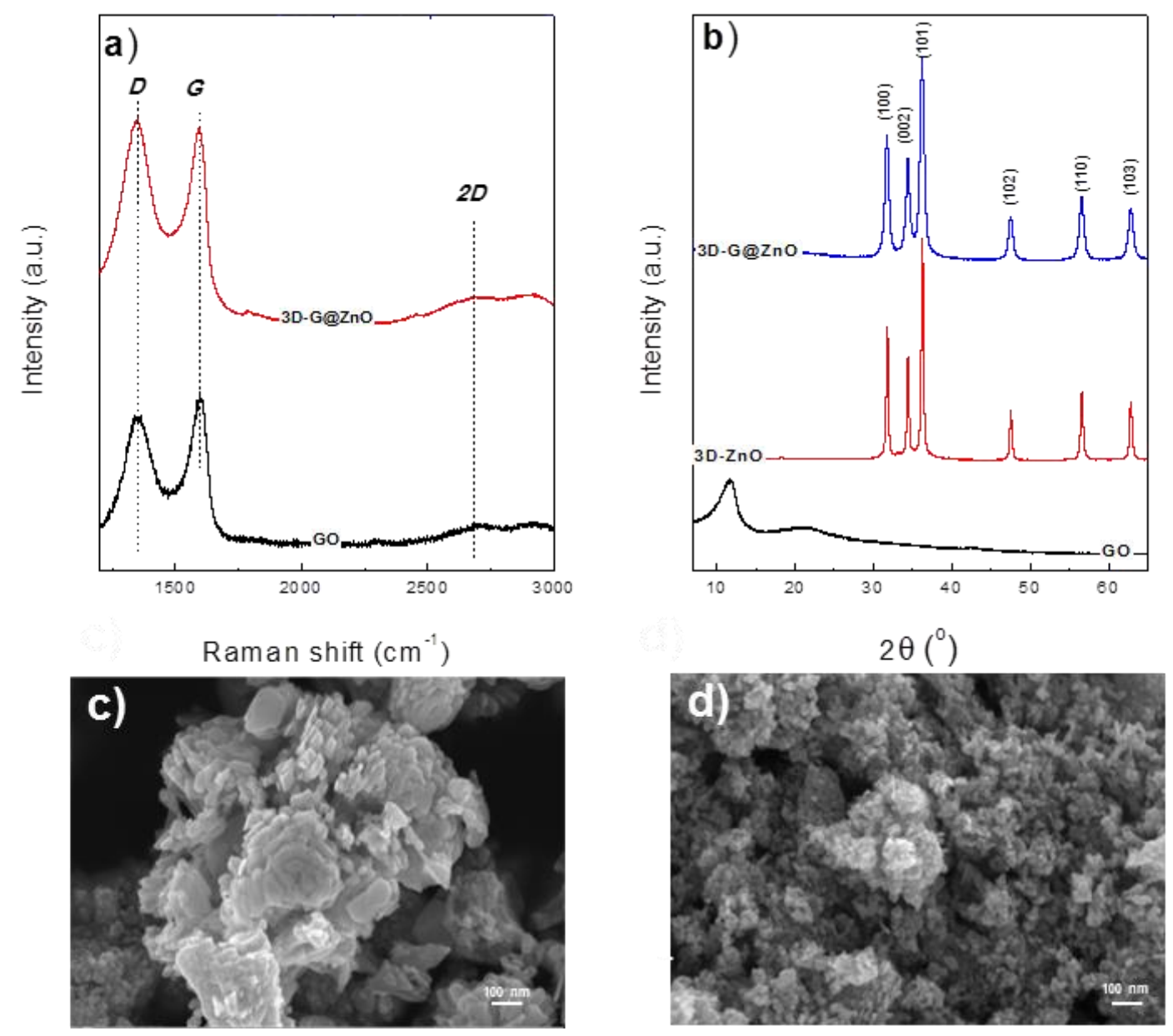

Figure 6. Structural characterization of the powder samples before addition of PtCo particles, a) Raman spectra; b) XRD patterns and SEM images of c) 3D-ZnO and d) 3D-G@ZnO.

The SEM images in Figures 6c and d confirm the differences in the morphology of the two powder samples. It can be seen that without graphene, $\mathrm{ZnO}$ forms well crystallized flakes which are stacking in large aggregates (Figure 6c). On the contrary, in the case of 3D-G@ZnO the 
morphology consists of agglomerated nanoparticles with much smaller size as compared to the uncovered sample (Figure 6d).

\section{Comparison of the redox stability of 3D powder samples}

The oxidation and reduction of $\mathrm{PtCo} / 3 \mathrm{D}-\mathrm{ZnO}$ and $\mathrm{PtCo} / 3 \mathrm{D}-\mathrm{G} @ \mathrm{ZnO}$ powder samples were studied in comparable to the model system conditions, with the addition of an initial step related to the decomposition of the precursors used for PtCo deposition. This step was carried out under 0.3 bar Ar instead of $\mathrm{O}_{2}$, since as revealed from the model system studies, the graphene defect density is enhanced in $\mathrm{O}_{2}$. The evolution of $\mathrm{Co}$ average valence during various gas treatments is plotted in Figure 7a, while some characteristic Co $2 p$ and Pt $4 \mathrm{f}$ spectra are shown in Figures $7 \mathrm{~b}$ and $7 \mathrm{c}$, respectively. Initially cobalt is in the $\mathrm{Co}^{2+}$ state as expected for the cobalt (II) acetate precursor used in the preparation. The cobalt (II) acetate is gradually decomposed upon annealing in Ar and about $70 \%$ of metallic Co is formed at $350{ }^{\circ} \mathrm{C}$ on both substrates as shown in Figure 7a. Although decomposition of cobalt (II) acetate under inert gas environment was reported to generate $\mathrm{CoO}$ as the final product, ${ }^{59}$ the low pressure and the addition of $\mathrm{H}_{2} \mathrm{PtCl}_{6} \cdot 6 \mathrm{H}_{2} \mathrm{O}$ used in our case evidently facilitates further decomposition of $\mathrm{CoO}$ to $\mathrm{Co}$.

After Ar treatment the samples were annealed in $\mathrm{H}_{2}$ with the aim to form reduced bimetallic PtCo as in the case of the model 2D sample. As displayed in Figure 7a, the substrate type influences the reduction of the cobalt oxide that remained after the decomposition of the precursor. $\mathrm{CoO}$ can be completely reduced at $250{ }^{\circ} \mathrm{C}$ on 3D-G@ZnO, while it resists reduction when supported on $3 \mathrm{D}-\mathrm{ZnO}$, even after annealing at $450{ }^{\circ} \mathrm{C}$. This is also confirmed in a second redox cycle were $\mathrm{PtCo} / 3 \mathrm{D}-\mathrm{ZnO}$ and $\mathrm{PtCo} / 3 \mathrm{D}-\mathrm{G} @ \mathrm{ZnO}$ are re-oxidized in 0.3 bar $\mathrm{O}_{2}$ and then reduced again in $\mathrm{H}_{2}$. As displayed in Figure 7a, after $250{ }^{\circ} \mathrm{C}$ in $\mathrm{O}_{2}$ cobalt was oxidized in both 
samples to a mixture of $\mathrm{CoO}$ and $\mathrm{Co}_{3} \mathrm{O}_{4}$, with minor influence of the graphene layer. The similarity in cobalt oxidation state in both samples confirms the observations in the model system (Figure 3c). In the following reduction cycle the support plays a significant role. In particular, cobalt oxides are reduced more efficiently on 3D-G@ $\mathrm{ZnO}$ as compared to 3D-ZnO, confirming the promotion effect of the graphene layer during the reduction step. This observation is in accordance with the results on the model system, which showed that the reduction of $\mathrm{Co}^{2+}$ is promoted by the graphene layer. Our model system studies proposed that this happens because graphene prevents oxygen transport from $\mathrm{ZnO}$ to the Co overlayer.

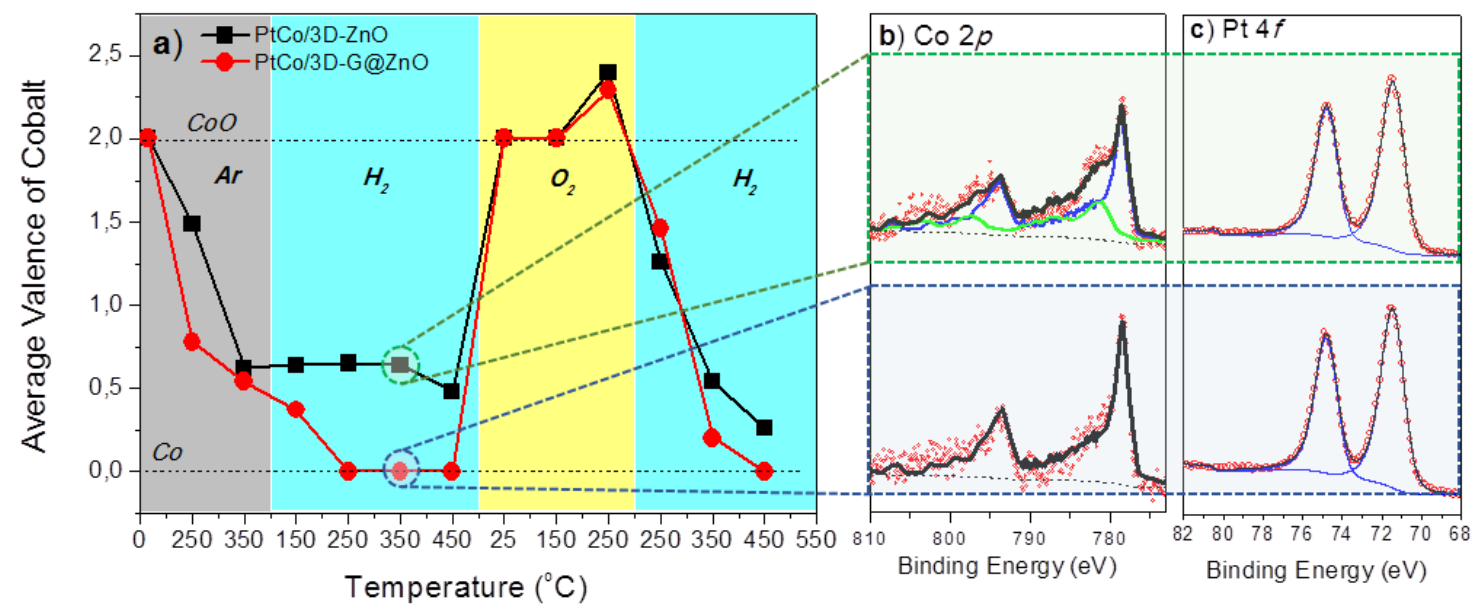

Figure 7. a) Co average valence state of $\mathrm{PtCo} / 3 \mathrm{D}-\mathrm{ZnO}$ and $\mathrm{PtCo} / 3 \mathrm{D}-\mathrm{G} @ \mathrm{ZnO}$ during the heating treatments under various gas environments. b) Typical Co $2 \mathrm{p}$ spectra of $\mathrm{PtCo} / 3 \mathrm{D}-\mathrm{ZnO}$ and PtCo/3D-G@ZnO after reduction in $\mathrm{H}_{2}$ at $350{ }^{\circ} \mathrm{C}$ as indicated by the circles in a). c) Typical Pt 4f spectra of PtCo/3D-ZnO and PtCo/3D-G@ZnO after oxidation in $\mathrm{O}_{2}$ at $250{ }^{\circ} \mathrm{C}$.

The surface oxidation state of $\mathrm{Pt}$ after decomposition in $\mathrm{Ar}$ and the $\mathrm{H}_{2}$ reduction step is deduced from the Pt 4f spectra included in Figure 7. For both samples only the Pt $4 \mathrm{f}$ peak at $71.4 \mathrm{eV}$ due to the metallic Pt appears after the decomposition of the precursor. After exposure at $0.3 \mathrm{mbar}_{2}$ 
at room temperature (Figure S3), an additional $\mathrm{Pt} 4 \mathrm{f}$ doublet at $72.7 \mathrm{eV}$ appears, which is ascribed to oxidized Pt species. The contribution of the oxidized Pt species increases up to $20 \%$ in the maximum $\mathrm{O}_{2}$ annealing temperature and disappears fast upon switching to $\mathrm{H}_{2}$ atmosphere (data not shown). Partial oxidation of $\mathrm{Pt}$ is in agreement with the observations in the 2D model catalyst, however there are some significant differences in the two cases. In particular, for powder samples the oxidation state of $\mathrm{Pt}$ is the same in both sample-types and is not influenced by the graphene coating. This contradicts the observations of the planar sample which showed that Pt oxidation is restricted in the presence of graphene.

The morphology of the samples after the redox treatment is presented in the TEM images of Figure 8. The low magnification images (Figures $8 \mathrm{a}$ and $8 \mathrm{c}$ ) suggest that on both substrates the PtCo NPs are well dispersed, with relatively uniform particle size and an average size of $4.5 \pm$ $1.8 \mathrm{~nm}$ and $5.3 \pm 2.2 \mathrm{~nm}$ for the $\mathrm{PtCo} / 3 \mathrm{D}-\mathrm{G} @ \mathrm{ZnO}$ and $\mathrm{PtCo} / 3 \mathrm{D}-\mathrm{ZnO}$, respectively (for the size distribution please refer to supporting information S4). The size of the particles on both substrates are therefore compatible and should not be accountable for the observed differences between them. In the HRTEM images of $\mathrm{PtCo} / 3 \mathrm{D}-\mathrm{ZnO}$ displayed in Figure $8 \mathrm{~b}$, the fringe spacing distance is measured $0.21 \mathrm{~nm}$, which corresponds to the $\mathrm{d}_{\mathrm{hkl}}$ of the (111) plane of the PtCo alloys (JCPDS no. 43-1358). In the case of PtCo/3D-G@ZnO, figure 8d presents a $\mathrm{d}_{\mathrm{hkl}}$ of $0.26 \mathrm{~nm}$ of (0002) plane of ZnO (JCPDS no. 36-1451), in agreement with its hexagonal wurtzite phase obtained from the XRD data. Also, Figure 8d clearly shows the few layer graphene coating at the outer shell of $\mathrm{ZnO}$ crystal (more TEM images can be found in supporting information Figure S5). This indicates that PtCo can be well loaded on the G@ZnO surface through impregnation method and the graphene layer has a good stability after the decomposition and reduction steps. 

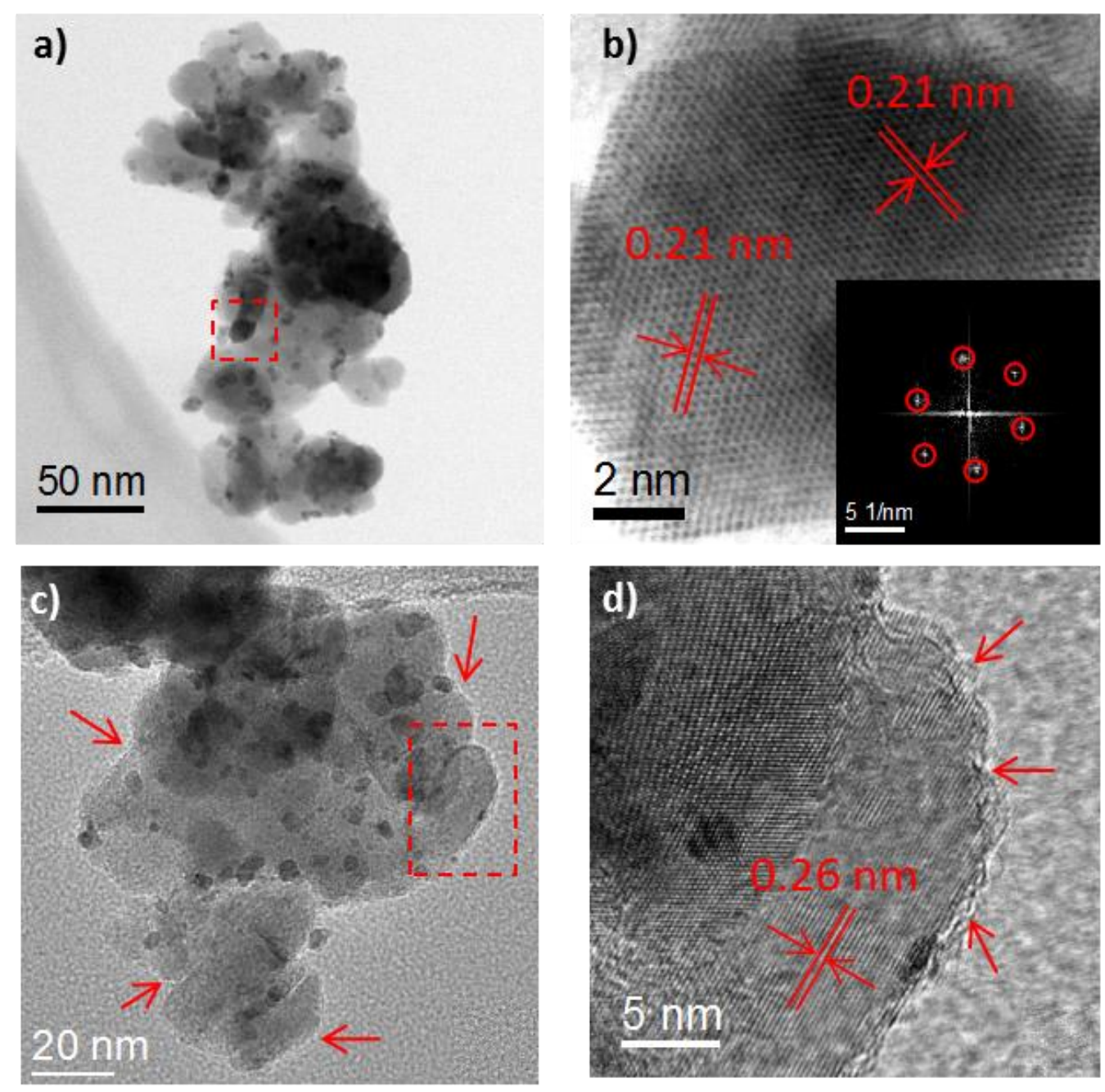

Figure 8 . (a) STEM Bright Field image of PtCo/3D-ZnO, (b) zoom on a CoPt particle with the corresponding FFT and (c,d) TEM images of PtCo/3D-G@ZnO after decomposition and reduction treatments. The graphene layers are indicated by red arrows.

A more detailed TEM investigation was carried out on the PtCo/3D-G@ZnO sample in order to determine the chemical order inside the PtCo NPs. Usually, electron diffraction and HRTEM can be used to obtain such information, but in our case the electron diffraction patterns are difficult to assign to a well-defined structure due to the presence of the crystallized $\mathrm{ZnO}$ support. The distance $d_{h k l}$ measured on Figure $8 d$ suggests that PtCo NPs displays A1 or L10 structure. To 
observe L10 ordered phase, the NP should be oriented in order to probe the [001] or [110] peaks. $^{60,61}$ For our PtCo NPs, we have observed several nanoparticles (isolated or on the support) in different orientations revealing a L10-type contrast. Figure 9 display such examples of oriented nanoparticles in the case of the sample PtCo/3D-G@ZnO, which shows a 001-type contrast: (1) the 001 peak is clearly present on the Fourier transform (FFT) by measuring the distance $d_{\text {hkl }}$ of $3.7 \AA$ on the NPs chosen in figures $9 a$ and 9c, (2) on Figure 9b, the high resolution profile taken on the green line evidences a periodicity corresponding to successive of a "Co-rich" and "Pt-rich" atomic planes along the [001] direction. These results confirm that the PtCo NPs supported on the G@ZnO display an L10-type structure.

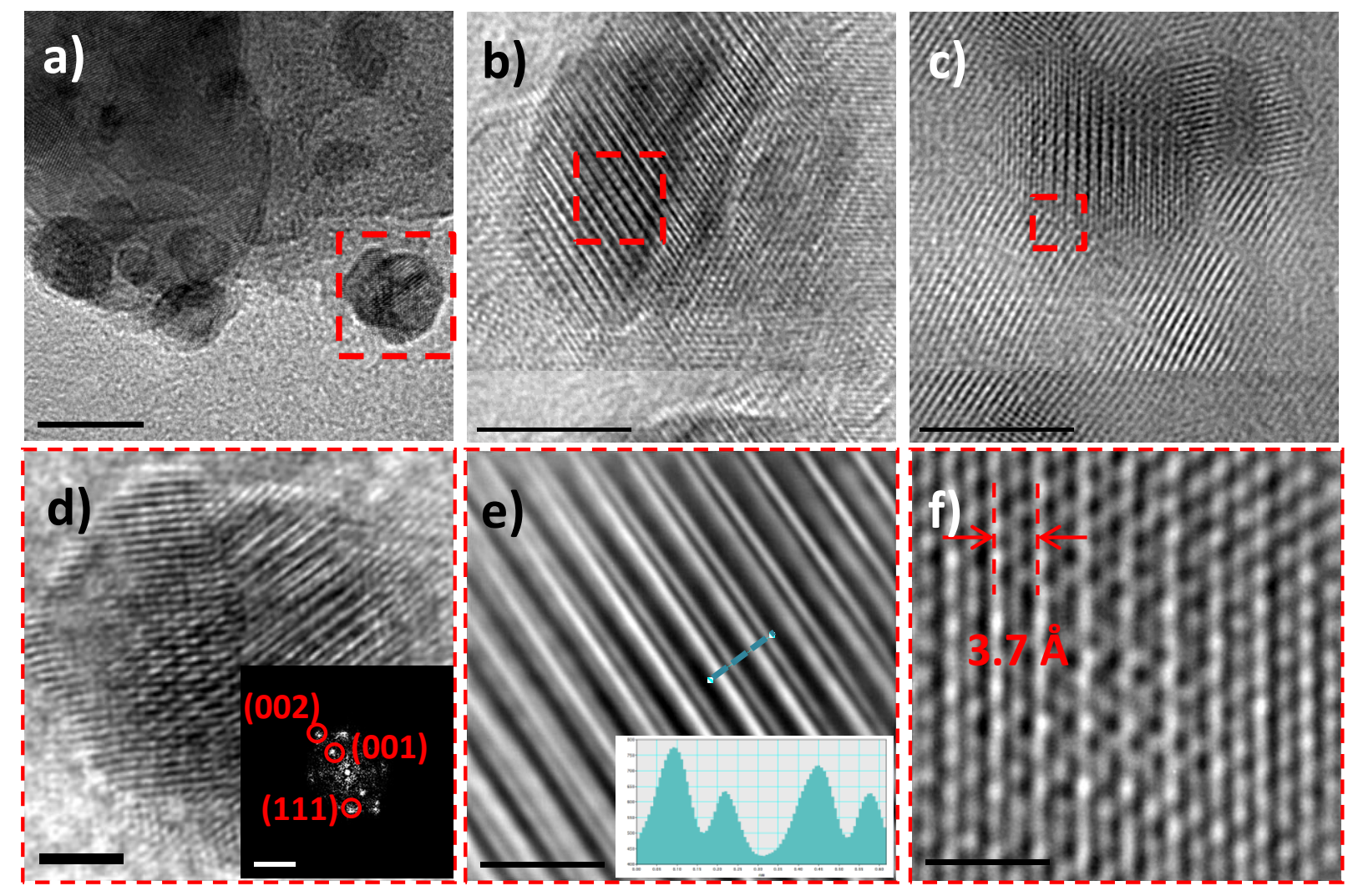

Figure 9. (a-c) TEM and HRTEM images of some typical oriented PtCo/3D-G@ZnO NPs displaying a L10-type chemical order (d)Zoom on the NP highlighted in (a) with in inset, the 
corresponding FFT showing a 001 peak. (e) Zoom of the region selected in (b) with in inset the corresponding profiles taken on the green line. (f) Zoom on the region selected in (c) revealing the $\mathrm{d}_{\mathrm{hkl}}$ distance corresponding to the (001)-type plane.

The stability of graphene is confirmed by the Raman spectra recorded after the redox gas treatments. These spectra, presented at supporting information S6, are quite similar to those measured at the fresh $\mathrm{G} @ \mathrm{ZnO}$ substrate. The differences in the fabrication method of the graphene coating, challenge for a straightforward comparison of the coating stability on the planar and powder systems. Nevertheless, the stability of graphene on powder samples is an encouraging result which illustrates that graphene can work as a coating layer in reactive oxidation/reduction environment.

\section{Correlation of planar and powder catalysts characteristics}

The above presented results demonstrate that the graphene layer between PtCo and $\mathrm{ZnO}$, restricts PtCo oxidation and facilitates cobalt reduction for both model and powder samples. Next, we attempt to correlate the characteristics between the two examined sample morphologies and rationalize the origin of some variations found between the two. Model and powder samples follow the same trend as the oxidation temperature increases, which is stepwise oxidation of Co to $\mathrm{CoO}$ and then to a mixture of $\mathrm{CoO}$ and $\mathrm{Co}_{3} \mathrm{O}_{4}$ (see Figure 3, Figure 7). The model system allowed observing a small difference at $50{ }^{\circ} \mathrm{C}$, where $\mathrm{Co}$ is less oxidized on PtCo/2D-G@ZnO as compared to $\mathrm{PtCo} / 2 \mathrm{D}-\mathrm{ZnO}$. This was attributed to the platinum surface enrichment, which is a direct effect of the enhanced surface mobility of PtCo adatoms over graphene. Although it was not possible to confirm this on the powder system, due to the complex morphology and the synthesis method followed, it is valuable information which reveals the intrinsic tendency of the 
material. Notably, the mobility of metal particles is enhanced by graphene and this will affect their final arrangement.

We turn now our attention to Pt, which according to the model system is oxidized only when it is in direct contact with $\mathrm{ZnO}$, but not on graphene. Pt oxidation on $\mathrm{ZnO}$ support is mainly restricted to their interface, as shown by the angle-resolved XPS measurements. This suggests that Pt oxidation is promoted by the strong metal/support interaction with $\mathrm{ZnO}$, and graphene plays the role of a barrier between the two. However, Pt oxidation does not seem to be affected by the support in the case of powder samples. The differences on Pt oxidation observed between $\mathrm{PtCo} / 2 \mathrm{D}-\mathrm{ZnO}$ and $\mathrm{PtCo} / 3 \mathrm{D}-\mathrm{ZnO}$ may originate from the crystalline structure of the $\mathrm{ZnO}$ support. Considering the strong preference of $\mathrm{Zn}$ ions for a tetrahedral coordination geometry and the coordinately unsaturated environment of $\mathrm{Zn}$ ions on the $\mathrm{Zn}$ (0001) plane, the oxidation of $\mathrm{Pt}$ on $\mathrm{ZnO}(0001)$ can be the result of the facile adsorption of oxygen molecules on this face, which at higher temperatures can diffuse to the interface with Pt and oxidize it. ${ }^{62}$

Concerning the reduction of cobalt oxides, significant improvement can be found on the graphene-coated substrates for both planar and powder samples. The graphene layer can mediate the $\mathrm{Co}-\mathrm{ZnO}$ interaction at high temperature and prevents oxidation of $\mathrm{Co}$ by $\mathrm{ZnO}$ and formation of $\mathrm{Co}_{\mathrm{x}} \mathrm{Zn}_{1-\mathrm{x}} \mathrm{O}$. The detailed system description provided by the $2 \mathrm{D}$ model can help to rationalize the PtCo properties and extent these finding also to the 3D powder sample. In particular, comparison of the $\mathrm{Co} / \mathrm{Pt}$ ratio between graphene and $\mathrm{ZnO}$ supported particles shows that this ratio is consistently lower in the case of graphene-coating (see Figure 5c). This manifests that the surface is enriched with $\mathrm{Pt}$ in the case of graphene and with $\mathrm{Co}$ in the case of $\mathrm{ZnO}$ support. One should primarily correlate this with the higher mobility of PtCo after deposition on graphene as compared to $\mathrm{ZnO}$. When PtCo is oxidized, there is an evident segregation of cobalt oxide on the 
surface, as shown by the increase of the $\mathrm{Co} / \mathrm{Pt}$ ratio, but still the surface of the graphenesupported particles remains more enriched in $\mathrm{Pt}$ as compared to $\mathrm{ZnO}$. This configuration is expected to have a pronounced effect on the reduction of cobalt of the consequent reduction step. As has been shown in previous studies, $\mathrm{H}_{2}$ adsorption and dissociation is facilitated by the presence of $\mathrm{Pt}$, which in turn, will catalyze the reduction of neighbouring cobalt oxide areas at lower temperatures.

Another factor that certainly complicates the comparison of planar and powder systems is the nature of graphene coating. CVD is currently the best method to grow high-quality graphene on planar surfaces and in large areas. However, for powder samples the use of graphene precursors, such as GO, is more appropriate. The choice of the fabrication method has a significant impact on the quality of the graphene coating. Notably in this work, CVD graphene is a single layer with low defect density, while graphene prepared by GO, is multilayer and has a much higher defect density. Raman spectra, of both planar and powder samples show that, independent of using CVD-grown graphene or a GO precursor, formation of defects on graphene is unavoidable after the redox treatment. Certainly, as proposed earlier, ${ }^{34}$ the few-layer graphene coated on powder $\mathrm{ZnO}$, is more stable than the single layer CVD-grown graphene used for the preparation of the model samples. In addition, it is expected that the oxygen functional groups present on the GO interact stronger with the $\mathrm{ZnO}$ surface leading to a well coated layer, which is not the case for CVD-grown graphene deposited on $\mathrm{ZnO}$ through wet transfer.

The graphene characteristics definitely affect the properties of the material and notably the PtCo particle morphology. As revealed by the AFM images of PtCo/2D-G@ZnO, PtCo maintains the homogeneous dispersed nanoparticle structure on the surface of graphene after deposition and redox treatments as compared to a flat morphology on bare $\mathrm{ZnO}(0001)$. Moreover, after several 
cycles of heating, the nanoparticles are agglomerated from $\sim 8 \mathrm{~nm}$ to $\sim 18 \mathrm{~nm}$ which is due to the low diffusion barriers of Pt and Co on the graphene layer. ${ }^{34}$ However, TEM images show similar sizes of PtCo NPs on bare graphene-coated ZnO powder. As shown in the Raman spectra (Figure 2a and Figure S4), the high intensity D peak indicates a high density of defects on the graphene coating layer. Those defects can play a role as anchoring sites for the nanoparticles, ${ }^{63}$ thus agglomeration of PtCo NPs on 3D-G@ZnO was not observed.

The above results inspire us to discuss some potential applications of the materials synthesized in this work. Cobalt is considered the most favourable metal for the Fischer-Tropsch synthesis to produce long chain hydrocarbons from syngas. ${ }^{1,64,65}$ Oxides supports, such as $\mathrm{Al}_{2} \mathrm{O}_{3}, \mathrm{SiO}_{2}$ and $\mathrm{TiO}_{2}$, are the most commonly used refractory supports for Co-based catalysts and is well accepted that their properties can strongly affect the performance of $\mathrm{Co}$. $\mathrm{SiO}_{2}$ weakly interacts with Co, which helps to lower the reduction temperature of Co oxide precursor, but fails to prevent Co particles from sintering upon prolonged use. On the other hand, supports like $\mathrm{Al}_{2} \mathrm{O}_{3}$ or $\mathrm{TiO}_{2}$ may improve the dispersion of $\mathrm{Co}$ and retard the crystallite diffusion, however, suffer from the formation of unreducible mixed oxides especially at high reduction temperatures. The PtCo/3D-G@ZnO prepared in this work proposes to use graphene coating on oxides, as a promising strategy to overcome these shortcomings. As shown above, taking the advantage of the graphene layers (weakly interaction but high density of anchor sites), the graphene-coated $\mathrm{ZnO}$ not only improves the reduction of Co oxides (Figure 7), but also limits the agglomeration to large Co particles (Figure S4). This is also consistent with the idea proposed in recent works to use carbon nanotubes ${ }^{66}$ or amorphous carbon as metal/support interlayers for FT synthesis catalysts. Beyond the applications in thermocatalysis, the PtCo/3D-ZnO and PtCo/3D-G@ZnO materials can also applied in photocalytic reactions, such as elimination of pollutants, water 
splitting and others. ${ }^{24,67-69}$ Adding of metals (such as Pt) on semiconductors are believed to retard electron-hole recombination and accordingly enhance the photocatalytic efficiency. ${ }^{68,69} \mathrm{In}$ the graphene/semiconductor composite systems, the role of graphene is reported to be multi fold, including tuning light absorption range and intensity, enhancing adsorption capacity and acting as photoelectron mediator and acceptor. ${ }^{67}$ Therefore, we expect that the PtCo/3D-G@ZnO sample could be a potentially high performance photocatalyst.

\section{CONCLUSIONS}

This work presents a combined approach of model/planar and realistic/powder catalysts formulation for the development of highly reducible cobalt catalysts supported on $\mathrm{ZnO}$. Due to the significantly lower degree of complexity of the model, as compared to the powder catalysts, the former is used to retrieve detailed information regarding the fundamental characteristics of the studied system. In particular, the model system reveals the arrangement of the PtCo particles, the oxidation mechanism and their effect on the graphene layer stability. Furthermore, it shows beyond doubt that the graphene coating on $\mathrm{ZnO}$ is effective to tune the reducibility of cobalt oxides toward lower temperatures. These results are used as a proof of concept in order to design and synthesize realistic 3D powder catalysts. Despite the fact that the complete reproduction of the model system features to the powder catalysts is challenging, if not unfeasible, we show that if an appropriate synthesis method is selected, the principal characteristics of the model system can be reproduced on the powder catalyst. Overall, our coordinated approach unavoidably illustrates that $\mathrm{Pt}$ promotion combined to $\mathrm{ZnO}$-coating of graphene can shift the reduction of cobalt oxides at significantly lower temperatures.

\section{ASSOCIATED CONTENT}


The average valence of cobalt and platinum recorded at two XPS take-off angles, the Pt $4 \mathrm{f}$ XPS spectra under various oxidation temperatures, statistics of the PtCo particle size calculated from TEM images, additional TEM images after reduction and Raman spectra after oxidation and reduction. This material is available free of charge via the Internet at http://pubs.acs.org.

\section{AUTHOR INFORMATION}

\section{Corresponding Author}

* spiros.zafeiratos@unistra.fr

\section{ACKNOWLEDGEMENTS}

W.L. would like to thank the China Scholarship Council (CSC) for a Ph.D grant during his stay at the ICPEES. We acknowledge the help of Dr. T. Dintzer for the SEM images and Dr V. Papaefthimiou for her support during the experiments.

\section{REFERENCES}

(1) Khodakov, A. Y.; Chu, W.; Fongarland, P. Advances in the Development of Novel Cobalt Fischer-Tropsch Catalysts for Synthesis of Long-Chain Hydrocarbons and Clean Fuels. Chem. Rev. 2007, 107 (5), 1692-1744.

(2) Wang, G.-H.; Hilgert, J.; Richter, F. H.; Wang, F.; Bongard, H.; Spliethoff, B.; Weidenthaler, C.; Schüth, F. Platinum-Cobalt Bimetallic Nanoparticles in Hollow Carbon Nanospheres for Hydrogenolysis of 5-Hydroxymethylfurfural. Nat. Mater. 2014, 13 (3), 293-300.

(3) Kababji, A. H.; Joseph, B.; Wolan, J. T. Silica-Supported Cobalt Catalysts for Fischer-Tropsch Synthesis: Effects of Calcination Temperature and Support Surface Area on 
Cobalt Silicate Formation. Catal. Letters 2009, 130 (1), 72-78.

(4) Turczyniak, S.; Teschner, D.; Machocki, A.; Zafeiratos, S. Effect of the Surface State on the Catalytic Performance of a $\mathrm{Co} / \mathrm{CeO} 2$ Ethanol Steam-Reforming Catalyst. J. Catal. 2016, 340, 321-330.

(5) Chu, W.; Xu, J.; Hong, J.; Lin, T.; Khodakov, A. Design of Efficient Fischer Tropsch Cobalt Catalysts via Plasma Enhancement: Reducibility and Performance (Review). Catal. Today 2015, 256 (P1), 41-48.

(6) Song, H.; Zhang, L.; Ozkan, U. S. Effect of Synthesis Parameters on the Catalytic Activity of Co-ZrO2 for Bio-Ethanol Steam Reforming. Green Chem. 2007, 9 (6), 686-694.

(7) Arnoldy, P. Temperature-Programmed Reduction of CoO/A12O3 Catalysts. J. Catal. $1985,93,38-54$.

(8) Papaefthimiou, V.; Dintzer, T.; Lebedeva, M.; Teschner, D.; H??vecker, M.; KnopGericke, A.; Schl??gl, R.; Pierron-Bohnes, V.; Savinova, E.; Zafeiratos, S. Probing MetalSupport Interaction in Reactive Environments: An in Situ Study of PtCo Bimetallic Nanoparticles Supported on TiO 2. J. Phys. Chem. C 2012, 116 (27), 14342-14349.

(9) Wakisaka, M.; Mitsui, S.; Hirose, Y.; Kawashima, K.; Uchida, H.; Watanabe, M. Electronic Structures of Pt-Co and Pt-Ru Alloys for CO-Tolerant Anode Catalysts in Polymer Electrolyte Fuel Cells Studied by EC-XPS. J. Phys. Chem. B 2006, 110 (46), 23489-23496.

(10) Zheng, F.; Alayoglu, S.; Guo, J.; Pushkarev, V.; Li, Y.; Glans, P.-A.; Chen, J.; Somorjai, G. In-Situ X-Ray Absorption Study of Evolution of Oxidation States and Structure of 
Cobalt in Co and CoPt Bimetallic Nanoparticles (4 Nm) under Reducing (H2) and Oxidizing (O2) Environments. Nano Lett. 2011, 11 (2), 847-853.

(11) Yu, W.; Porosoff, M. D.; Chen, J. G. Review of Pt-Based Bimetallic Catalysis: From Model Surfaces to Supported Catalysts. Chem. Rev. 2012, 112 (11), 5780-5817.

(12) Xu, H.; Fu, Q.; Guo, X.; Bao, X. Architecture of Pt-Co Bimetallic Catalysts for Catalytic CO Oxidation. ChemCatChem 2012, 4 (10), 1645-1652.

(13) Xu, X.; Fu, Q.; Wei, M.; Wu, X.; Bao, X. Comparative Studies of Redox Behaviors of Pt$\mathrm{Co} / \mathrm{SiO} 2$ and $\mathrm{Au}-\mathrm{Co} / \mathrm{SiO} 2$ Catalysts and Their Activities in CO Oxidation. Catal. Sci. Technol. 2014, 4 (9), 3151.

(14) Gnanamani, M. K.; Ribeiro, M. C.; Ma, W.; Shafer, W. D.; Jacobs, G.; Graham, U. M.; Davis, B. H. Fischer-Tropsch Synthesis: Metal-Support Interfacial Contact Governs Oxygenates Selectivity over CeO2 Supported Pt-Co Catalysts. Appl. Catal. A Gen. 2011, $393(1-2), 17-23$.

(15) Stamenkovic, V. R.; Mun, B. S.; Arenz, M.; Mayrhofer, K. J. J.; Lucas, C. A.; Wang, G.; Ross, P. N.; Markovic, N. M. Trends in Electrocatalysis on Extended and Nanoscale PtBimetallic Alloy Surfaces. Nat. Mater. 2007, 6 (3), 241-247.

(16) Liao, H.; Fisher, A.; Xu, Z. J. Surface Segregation in Bimetallic Nanoparticles: A Critical Issue in Electrocatalyst Engineering. Small 2015, 11 (27), 3221-3246.

(17) Bezemer, G. L.; Bitter, J. H.; Kuipers, H. P. C. E.; Oosterbeek, H.; Holewijn, J. E.; Xu, X.; Kapteijn, F.; Dillen, a J. Van; Jong, K. P. De. Cobalt Particle Size Effects in the Fischer - Tropsch Reaction Studied with Carbon Nanofiber Supported Catalysts. Am. 
Chem. Soc. 2006, 128 (12), 3956-3964.

(18) K. S. Novoselov S. V. Morozov, D. Jiang, Y. Zhang, S. V. Dubonos, I. V. Grigorieva, A. A. Firsov, A. K. G. Electric Field Effect in Atomically Thin Carbon Films. Science (80-. ). 306 (5696), 666-669.

(19) Geim, A. K.; Novoselov, K. S. The Rise of Graphene. Nat. Mater. 2007, 6 (3), 183-191.

(20) Novoselov, K. S.; Fal'ko, V. I.; Colombo, L.; Gellert, P. R.; Schwab, M. G.; Kim, K. A Roadmap for Graphene. Nature 2012, 490 (7419), 192-200.

(21) Haag, D.; Kung, H. H. Metal Free Graphene Based Catalysts: A Review. Top. Catal. 2014, 57 (6-9), 762-773.

(22) Machado, B. F.; Serp, P. Graphene-Based Materials for Catalysis. Catal. Sci. Technol. 2012, 2 (1), 54-75.

(23) Xiang, Q.; Yu, J.; Jaroniec, M. Graphene-Based Semiconductor Photocatalysts. Chem. Soc. Rev. 2012, 41 (2), 782.

(24) Luo, W.; Zafeiratos, S. A Brief Review of Synthesis and Catalytic Applications of Graphene-Coated Oxides. ChemCatChem 2017, 9, 2432-2442.

(25) Xiong, H.; Schwartz, T. J.; Andersen, N. I.; Dumesic, J. A.; Datye, A. K. GraphiticCarbon Layers on Oxides: Toward Stable Heterogeneous Catalysts for Biomass Conversion Reactions. Angew. Chemie - Int. Ed. 2015, 54 (27), 7939-7943.

(26) Karimi, S.; Tavasoli, A.; Mortazavi, Y.; Karimi, A. Enhancement of Cobalt Catalyst Stability in Fischer-Tropsch Synthesis Using Graphene Nanosheets as Catalyst Support. 
Chem. Eng. Res. Des. 2015, 104, 713-722.

(27) Zhongzhe Wei; Chen, Y.; Wang, J.; Su, D.; Tang, M.; Mao, S.; Wang, Y. Cobalt Encapsulated in N-Doped Graphene Layers: An Efficient and Stable Catalyst for Hydrogenation of Quinoline Compounds. ACS Catal. 2016, 6, 5816-5822.

(28) Kamat, P. V. Graphene-Based Nanoarchitectures. Anchoring Semiconductor and Metal Nanoparticles on a Two-Dimensional Carbon Support. J. Phys. Chem. Lett. 2010, 1 (2), $520-527$.

(29) Moussa, S. O.; Panchakarla, L. S.; Ho, M. Q.; El-Shall, M. S. Graphene-Supported, IronBased Nanoparticles for Catalytic Production of Liquid Hydrocarbons from Synthesis Gas: The Role of the Graphene Support in Comparison with Carbon Nanotubes. ACS Catal. 2014, 4 (2), 535-545.

(30) Liang, Y.; Li, Y.; Wang, H.; Zhou, J.; Wang, J.; Regier, T.; Dai, H. Co3O4 4 Nanocrystals on Graphene as a Synergistic Catalyst for Oxygen Reduction Reaction. Nat. Mater. 2011, $10(10), 780-786$.

(31) Zhang, Y.; Tang, Z.; Fu, X.; Xu, Y. TiO2-Graphene Nanocomposites for Gas-Phase Photocatalytic Degradation of Volatile Aromatic Pollutant: Is TiO2-Graphene Truly Different from Other TiO2-Carbon Composite Materials? ACS Nano 2010, 4 (12), 73037314.

(32) Ashkarran, A. A.; Mohammadi, B. ZnO Nanoparticles Decorated on Graphene Sheets through Liquid Arc Discharge Approach with Enhanced Photocatalytic Performance under Visible-Light. Appl. Surf. Sci. 2015, 342, 112-119. 
(33) Luo, W.; Zafeiratos, S. Graphene-Coated $\mathrm{ZnO}$ and $\mathrm{SiO} 2$ as Supports for $\mathrm{CoO}$ Nanoparticles with Enhanced Reducibility. ChemPhysChem 2016, 17 (29), 3055-3061.

(34) Luo, W.; Zafeiratos, S. Tuning Morphology and Redox Properties of Cobalt Particles Supported on Oxides by an in between Graphene Layer. J. Phys. Chem. C 2016, 120 (26), $14130-14139$.

(35) Luo, W.; Doh, W. H.; Law, Y. T.; Aweke, F.; Ksiazek-Sobieszek, A.; Sobieszek, A.; Salamacha, L.; Skrzypiec, K.; Machocki, A.; Zafeiratos, S.; Le Normand, F.; Machocki, A.; Zafeiratos, S. Single-Layer Graphene as an Effective Mediator of the Metal-Support Interaction. J. Phys. Chem. Lett. 2014, 5 (11), 1837-1844.

(36) Son, D. I.; Kwon, B. W.; Park, D. H.; Seo, W.-S.; Yi, Y.; Angadi, B.; Lee, C.-L.; Choi, W. K. Emissive ZnO-graphene Quantum Dots for White-Light-Emitting Diodes. Nat. Nanotechnol. 2012, 7 (7), 465-471.

(37) Hummers, W. S.; Offeman, R. E. Preparation of Graphitic Oxide. J. Am. Chem. Soc. 1958, $80(6), 1339-1339$.

(38) Karhu, H.; Kalantar, A.; Väyrynen, I. J.; Salmi, T.; Murzin, D. Y. XPS Analysis of Chlorine Residues in Supported Pt and Pd Catalysts with Low Metal Loading. Appl. Catal. A Gen. 2003, 247 (2), 283-294.

(39) Biesinger, M. C.; Lau, L. W. M.; Gerson, A. R.; Smart, R. S. C. Resolving Surface Chemical States in XPS Analysis of First Row Transition Metals, Oxides and Hydroxides: Sc, Ti, V, Cu and Zn. Appl. Surf. Sci. 2010, 257 (3), 887-898.

(40) Wöll, C. The Chemistry and Physics of Zinc Oxide Surfaces. Prog. Surf. Sci. 2007, 82 (2- 
3), $55-120$.

(41) Ferrari, A. C.; Basko, D. M. Raman Spectroscopy as a Versatile Tool for Studying the Properties of Graphene. Nat. Nanotechnol. 2013, 8 (4), 235-246.

(42) Ferrari, A. C.; Meyer, J. C.; Scardaci, V.; Casiraghi, C.; Lazzeri, M.; Mauri, F.; Piscanec, S.; Jiang, D.; Novoselov, K. S.; Roth, S.; Geim, A. K. Raman Spectrum of Graphene and Graphene Layers. Phys. Rev. Lett. 2006, 97 (18), 187401.

(43) Gong, C.; Mcdonnell, S.; Qin, X.; Azcatl, A.; Dong, H.; Chabal, Y. J.; Cho, K.; Wallace, R. M. Realistic Metal-Graphene Contact Structures. ACS Nano 2014, 8 (1), 642-649.

(44) Iqbal, M. W. Z.; Singh, A. K.; Iqbal, M. W. Z.; Eom, J. Raman Fingerprint of Doping due to Metal Adsorbates on Graphene. J. Phys. Condens. Matter 2012, 24 (33), 335301.

(45) Hyman, M. P.; Martono, E.; Vohs, J. M. Studies of the Structure and Interfacial Chemistry of Co Layers on ZnO(0001). J. Phys. Chem. C 2010, 114 (40), 16892-16899.

(46) Liao, Q.; Zhang, H. J.; Wu, K.; Li, H. Y.; Bao, S. N.; He, P. Nucleation and Growth of Monodispersed Cobalt Nanoclusters on Graphene Moiré on $\mathrm{Ru}(0001)$. Nanotechnology 2011, $22(12), 125303$.

(47) Lee, Y.; Lim, K.; Chung, Y.; Whang, C.; Jeon, Y. XPS Core-Level Shifts and XANES Studies of Cu-Pt and Co-Pt Alloys. Surf. Interface Anal. 2000, 30 (July 1999), 475-478.

(48) Vasquez, Y.; Sra, A. K.; Schaak, R. E. One-Pot Synthesis of Hollow Superparamagnetic CoPt Nanospheres. J Am Chem Soc 2005, 127 (36), 12504-12505.

(49) Von Weber, A.; Anderson, S. L. Electrocatalysis by Mass-Selected Ptn Clusters. Acc. 
Chem. Res. 2016, 49 (11), 2632-2639.

(50) Isaifan, R. J.; Ntais, S.; Baranova, E. A. Particle Size Effect on Catalytic Activity of Carbon-Supported Pt Nanoparticles for Complete Ethylene Oxidation. Appl. Catal. A Gen. 2013, 464-465, 87-94.

(51) Jiang, Z.-Z.; Wang, Z.-B.; Chu, Y.-Y.; Gu, D.-M.; Yin, G.-P. Ultrahigh Stable Carbon Riveted Pt/TiO2-C Catalyst Prepared by in Situ Carbonized Glucose for Proton Exchange Membrane Fuel Cell. Energy Environ. Sci. 2011, 4 (3), 728.

(52) Naitabdi, A.; Fagiewicz, R.; Boucly, A.; Olivieri, G.; Bournel, F.; Tissot, H.; Xu, Y.; Benbalagh, R.; Silly, M. G.; Sirotti, F.; Gallet, J. J.; Rochet, F. Oxidation of Small Supported Platinum-Based Nanoparticles under Near-Ambient Pressure Exposure to Oxygen. Top. Catal. 2016, 59 (5-7), 550-563.

(53) Abe, Y.; Kawamura, M.; Sasaki, K. Preparation of PtO and $\alpha-\mathrm{PtO} 2$ Thin Films by Reactive Sputtering and Their Electrical Properties. Jpn. J. Appl. Phys. 1999, 38 (Part 1, No. 4A), 2092-2096.

(54) Hirunsit, P.; Balbuena, P. B. Effects of Water and Electric Field on Atomic Oxygen Adsorption on Pt-Co Alloys. Surf. Sci. 2009, 603 (21), 3239-3248.

(55) Grimm, S.; Schweiger, M.; Eigler, S.; Zaumseil, J. High-Quality Reduced Graphene Oxide by CVD-Assisted Annealing. J. Phys. Chem. C 2016, 120 (5), 3036-3041.

(56) Weng, B.; Yang, M. Q.; Zhang, N.; Xu, Y. J. Toward the Enhanced Photoactivity and Photostability of $\mathrm{ZnO}$ Nanospheres via Intimate Surface Coating with Reduced Graphene Oxide. J. Mater. Chem. A 2014, 2 (24), 9380-9389. 
(57) Bu, Y.; Chen, Z.; Li, W.; Hou, B. Highly Efficient Photocatalytic Performance of Graphene-ZnO.pdf. ACS Appl. Mater. Interfaces 2013, 5, 12361-12368.

(58) Khodakov, A. Y.; Griboval-Constant, A.; Bechara, R.; Villain, F. Pore-Size Control of Cobalt Dispersion and Reducibility in Mesoporous Silicas. J. Phys. Chem. B 2001, 105 (40), 9805-9811.

(59) Wanjun, T.; Donghua, C. Mechanism of Thermal Decomposition of Cobalt Acetate Tetrahydrate. Chem. Pap. 2007, 61 (4), 329-332.

(60) Tournus, F.; Tamion, A.; Blanc, N.; Hannour, A.; Bardotti, L.; Pr??vel, B.; Ohresser, P.; Bonet, E.; Epicier, T.; Dupuis, V. Evidence of L 10 Chemical Order in CoPt Nanoclusters: Direct Observation and Magnetic Signature. Phys. Rev. B - Condens. Matter Mater. Phys. 2008, $77(14), 144411$.

(61) Andreazza, P.; Pierron-Bohnes, V.; Tournus, F.; Andreazza-Vignolle, C.; Dupuis, V. Structure and Order in Cobalt/platinum-Type Nanoalloys: From Thin Films to Supported Clusters. Surf. Sci. Rep. 2015, 70 (2), 188-258.

(62) Jang, E. S.; Won, J. H.; Hwang, S. J.; Choy, J. H. Fine Tuning of the Face Orientation of ZnO Crystals to Optimize Their Photocatalytic Activity. Adv. Mater. 2006, 18 (24), 33093312.

(63) Zhang, B.; Su, D. S. Probing the Metal - Support Interaction in Carbon- Supported Catalysts by Using Electron Microscopy. ChemCatChem 2015, 7, 3639-3645.

(64) Liu, Y.; Luo, J.; Shin, Y.; Moldovan, S.; Ersen, O.; Hébraud, A.; Schlatter, G.; Pham-Huu, C.; Meny, C. Sampling the Structure and Chemical Order in Assemblies of Ferromagnetic 
Nanoparticles by Nuclear Magnetic Resonance. Nat. Commun. 2016, 7, 11532.

(65) Tsakoumis, N. E.; Rønning, M.; Borg, Ø.; Rytter, E.; Holmen, A. Deactivation of Cobalt Based Fischer-Tropsch Catalysts: A Review. In Catalysis Today; 2010; Vol. 154, pp 162182.

(66) Liu, Y.; Luo, J.; Girleanu, M.; Ersen, O.; Pham-Huu, C.; Meny, C. Efficient Hierarchically Structured Composites Containing Cobalt Catalyst for Clean Synthetic Fuel Production from Fischer-Tropsch Synthesis. J. Catal. 2014, 318, 179-192.

(67) Zhang, N.; Yang, M.; Liu, S.; Sun, Y.; Xu, Y. Waltzing with the Versatile Platform of Graphene to Synthesize Composite Photocatalysts. Chem. Rev. 2015, 115, 10307-10377.

(68) Wang, W. N.; An, W. J.; Ramalingam, B.; Mukherjee, S.; Niedzwiedzki, D. M.; Gangopadhyay, S.; Biswas, P. Size and Structure Matter: Enhanced CO2 Photoreduction Efficiency by Size-Resolved Ultrafine Pt Nanoparticles on TiO2 Single Crystals. J. Am. Chem. Soc. 2012, 134 (27), 11276-11281.

(69) Zhai, C.; Zhu, M.; Bin, D.; Wang, H.; Du, Y.; Wang, C.; Yang, P. Visible-Light-Assisted Electrocatalytic Oxidation of Methanol Using Reduced Graphene Oxide Modified Pt Nanoflowers-TiO 2 Nanotube Arrays. ACS Appl. Mater. Interfaces 2014, 6 (20), 1775317761. 